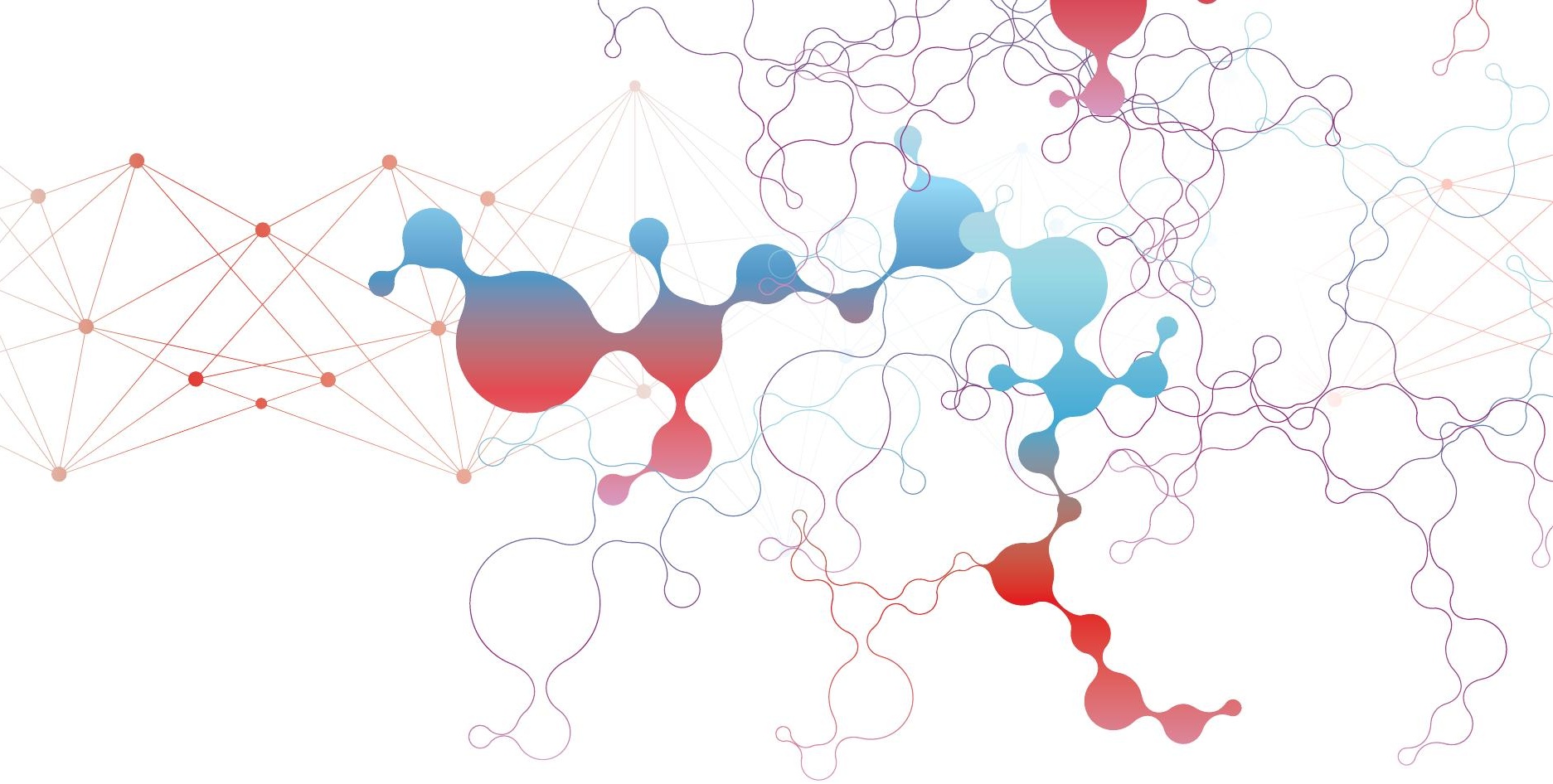

\title{
Informe sobre el impacto económico en América Latina y el Caribe de la enfermedad por coronavirus (COVID-19)
}

Estudio elaborado por la Comisión Económica para América Latina y el Caribe (CEPAL) en respuesta a la solicitud realizada por el Gobierno de México en el ejercicio de la Presidencia Pro Témpore de la Comunidad de Estados Latinoamericanos y Caribeños (CELAC) durante la Reunión Ministerial Virtual sobre Asuntos de Salud para la Atención y el Seguimiento de la Pandemia COVID-19 en América Latina y el Caribe celebrada el 26 de marzo de 2020
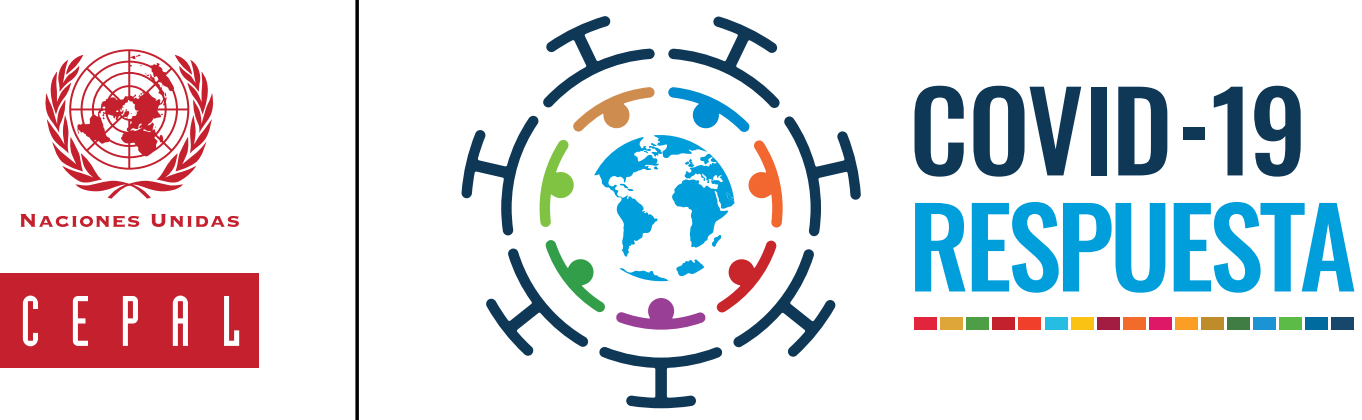

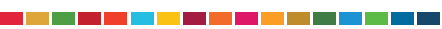




\section{Gracias por su interés en esta publicación de la CEPAL}

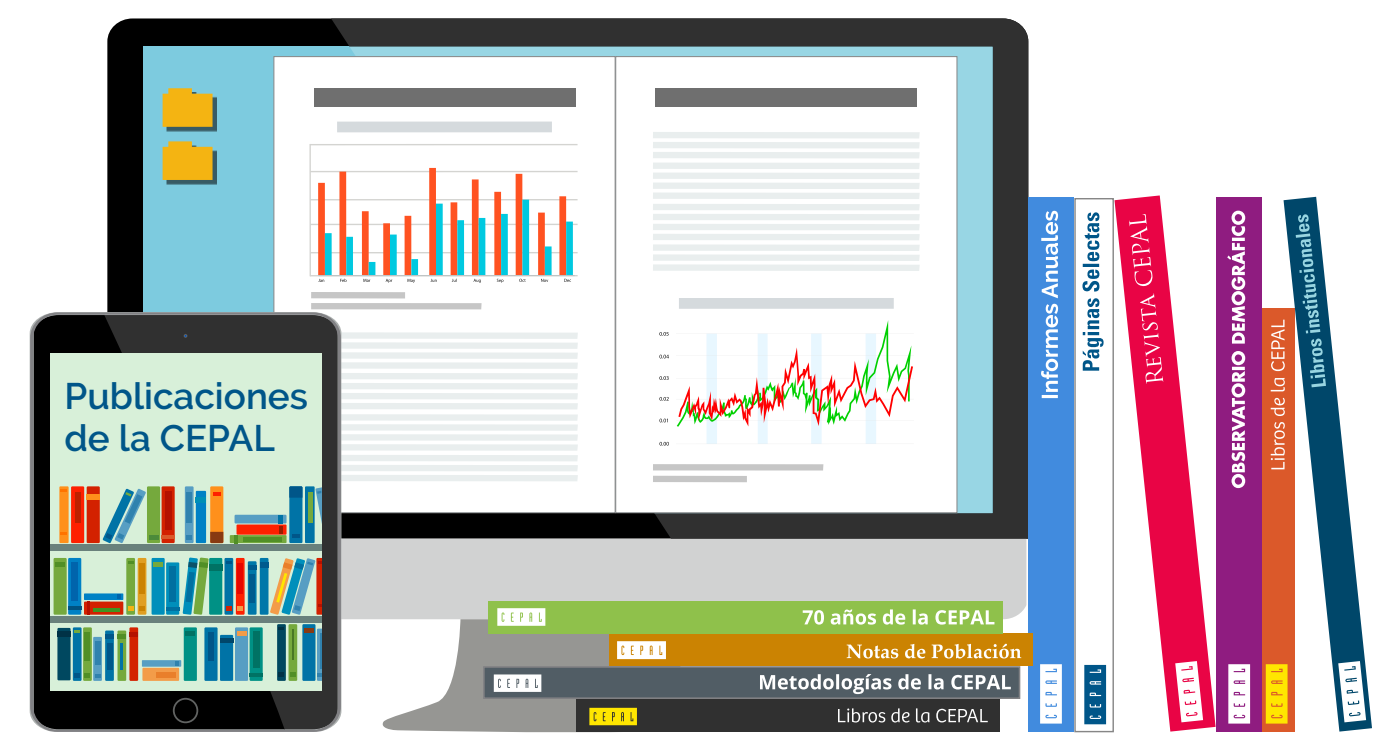

Si desea recibir información oportuna sobre nuestros productos editoriales y actividades, le invitamos a registrarse. Podrá definir sus áreas de interés y acceder a nuestros productos en otros formatos.

\section{Deseo registrarme}

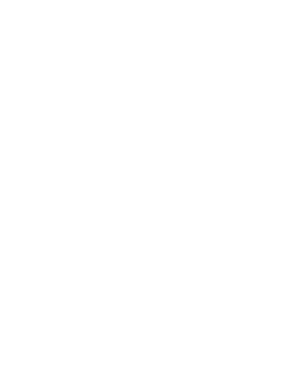

www.cepal.org/es/publications

ff facebook.com/publicacionesdelacepal

P www.cepal.org/apps 


\section{Informe sobre impacto económico en América Latina y el Caribe de la enfermedad por coronavirus (COVID-19)}

Estudio elaborado por la Comisión Económica para América Latina y el Caribe (CEPAL) en respuesta a la solicitud realizada por el Gobierno de México en el ejercicio de la Presidencia Pro Témpore de la Comunidad de Estados Latinoamericanos y Caribeños (CELAC) durante la Reunión Ministerial Virtual sobre Asuntos de Salud para la Atención y el Seguimiento de la Pandemia COVID-19 en América Latina y el Caribe celebrada el 26 de marzo de 2020
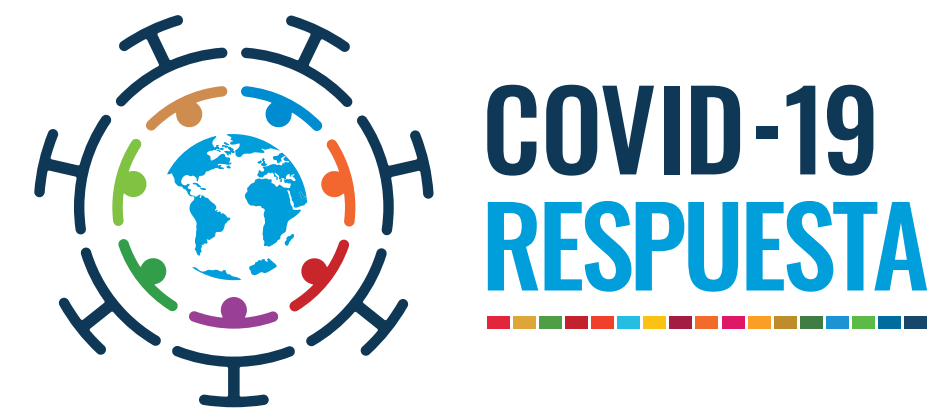


\section{Alicia Bárcena \\ Secretaria Ejecutiva}

\section{Mario Cimoli}

Secretario Ejecutivo Adjunto

Raúl García-Buchaca

Secretario Ejecutivo Adjunto

para Administración y Análisis de Programas

\section{Ricardo Pérez}

Director de la División de Publicaciones y Servicios Web

Este documento fue elaborado por la Comisión Económica para América Latina y el Caribe (CEPAL) en respuesta a la solicitud realizada por el Gobierno de México en el ejercicio de la Presidencia Pro Témpore de la Comunidad de Estados Latinoamericanos y Caribeños (CELAC) durante la Reunión Ministerial Virtual sobre Asuntos de Salud para la Atención y el Seguimiento de la Pandemia COVID-19 en América Latina y el Caribe celebrada el 26 de marzo de 2020.

Los límites y los nombres que figuran en los mapas incluidos en este documento no implican su apoyo o aceptación oficial por las Naciones Unidas.

Publicación de las Naciones Unidas

LC/TS.2020/45

Distribución: L

Copyright (C) Naciones Unidas, 2020

Todos los derechos reservados

Impreso en Naciones Unidas, Santiago

S.20-00313

Esta publicación debe citarse como: Comisión Económica para América Latina y el Caribe (CEPAL), Informe sobre el impacto económico en América Latina y el Caribe de la enfermedad por coronavirus (COVID-19): estudio elaborado por la Comisión Económica para América Latina y el Caribe (CEPAL) en respuesta a la solicitud realizada por el Gobierno de México en el ejercicio de la Presidencia Pro Témpore de la Comunidad de Estados Latinoamericanos y Caribeños (CELAC) durante la Reunión Ministerial Virtual sobre Asuntos de Salud para la Atención y el Seguimiento de la Pandemia COVID-19 en América Latina y el Caribe celebrada el 26 de marzo de 2020 (LC/TS.2020/45), Santiago, 2020.

La autorización para reproducir total o parcialmente esta obra debe solicitarse a la Comisión Económica para América Latina y el Caribe (CEPAL), División de Publicaciones y Servicios Web, publicaciones.cepal@un.org. Los Estados Miembros de las Naciones Unidas y sus instituciones gubernamentales pueden reproducir esta obra sin autorización previa. Solo se les solicita que mencionen la fuente e informen a la CEPAL de tal reproducción. 


\section{Îndice}

Informe para la Comunidad de Estados Latinoamericanos y Caribeños (CELAC) .......................................

I. Los impactos económicos y sociales de la pandemia de la enfermedad por coronavirus (COVID-19) en América Latina y el Caribe

A. Antes de la pandemia la región tenía el menor crecimiento económico en décadas y un limitado espacio

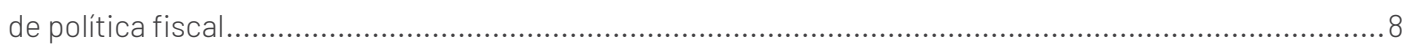

B. La pandemia llevará a la mayor contracción de la actividad económica en la historia de la región ........... 10

C. La economía de los países de América Latina y el Caribe en 2020: la CEPAL proyecta una contracción de la actividad del $5,3 \%$ y casi 30 millones más de pobres ........................................................... 14

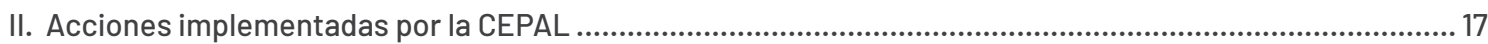

A. Observatorio COVID-19 en América Latina y el Caribe: impacto económico y social ...............................17

B. Red de Transmisión del Conocimiento de la Conferencia Estadística de las Américas de la CEPAL: ideas y recomendaciones sobre la continuidad de las principales operaciones estadísticas durante

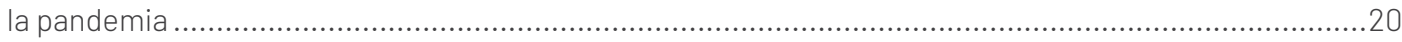

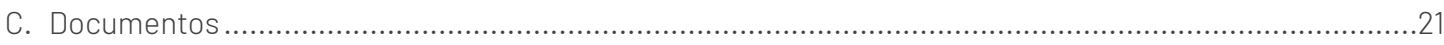

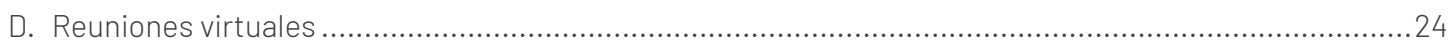

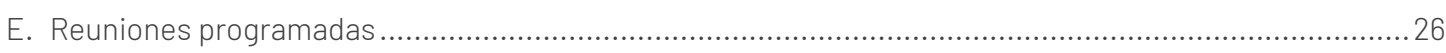

III. Políticas para enfrentar los efectos económicos y sociales de la pandemia.......................................... 27

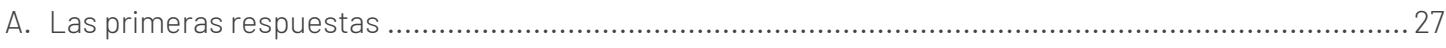

B. Políticas para seguir avanzando en la mitigación de los efectos de la crisis ......................................30

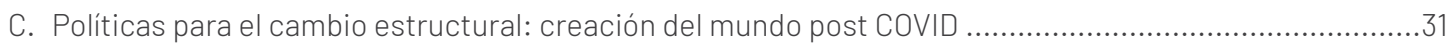

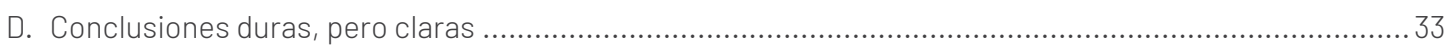

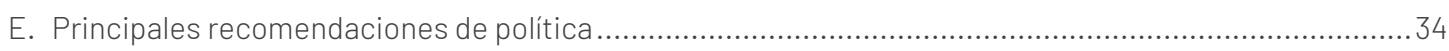

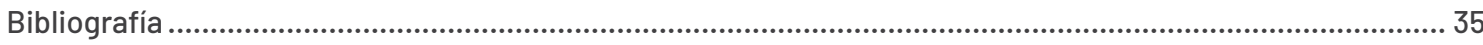





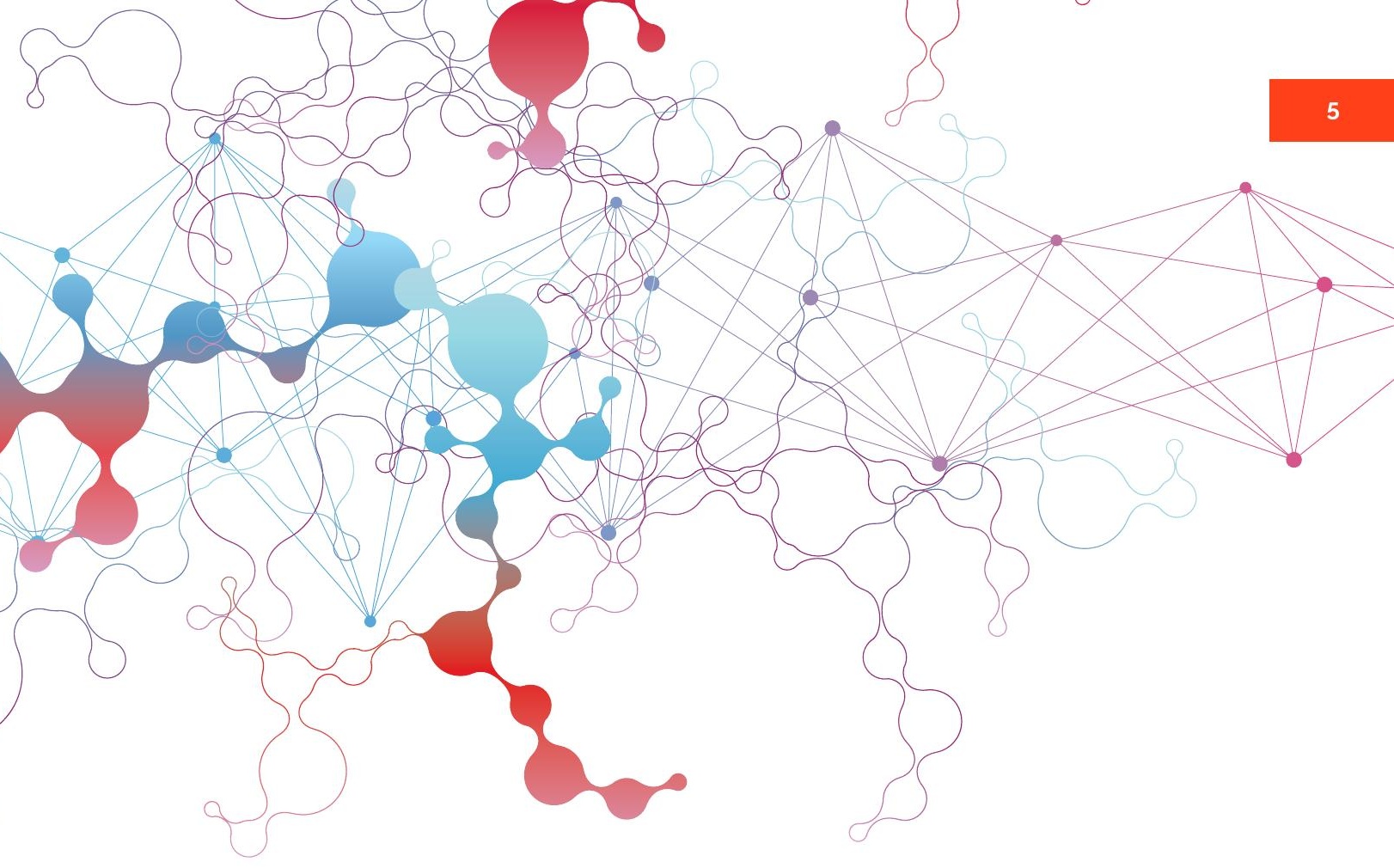

\section{Informe para la Comunidad de Estados Latinoamericanos y Caribeños (CELAC)}

El 26 de marzo de 2020, el Gobierno de México convocó la Reunión Ministerial Virtual sobre Asuntos de Salud para la Atención y el Seguimiento de la Pandemia COVID-19 en América Latina y el Caribe, en la que participaron cancilleres, ministros y representantes del área de la salud de 30 países de la Comunidad de Estados Latinoamericanos y Caribeños (CELAC), así como de organizaciones regionales.

Como resultado de la reunión, la CELAC formó una alianza estratégica con la Comisión Económica para América Latina y el Caribe (CEPAL) y la Organización de las Naciones Unidas para la Alimentación y la Agricultura (FAO) para complementar la estrategia regional ante la pandemia del COVID-19 en América Latina y el Caribe.

En respuesta a esa solicitud, el 3 de abril, la CEPAL puso en marcha el Observatorio COVID-19 en América Latina y el Caribe: Impacto Económico y Social, para continuar brindando apoyo al seguimiento de la propagación del virus a mediano y largo plazo, así como de las medidas de política que los países adopten para contener la pandemia y reducir sus impactos económicos y sociales.

Como bien público regional, el Observatorio genera y divulga información para apoyar la formulación de decisiones basadas en evidencia por parte de los gobiernos, las empresas, las instituciones académicas y las organizaciones de la sociedad civil de los 33 países de la región latinoamericana y caribeña. 

En este informe en respuesta a la solicitud de la CELAC se consideran tres temas: los impactos económicos y sociales de la pandemia en la región, las acciones puestas en marcha por la CEPAL y, con base en los dos puntos anteriores, un conjunto de recomendaciones de política para enfrentar la pandemia y sus efectos en distintos ámbitos.

\section{A. Antes de la pandemia la región tenía el menor crecimiento económico en décadas y un limitado espacio de política fiscal}

La pandemia del COVID-19 impactó América Latina y el Caribe en un momento de debilidad de su economía y de vulnerabilidad macroeconómica. En el decenio posterior a la crisis financiera mundial (2010-2019), la tasa de crecimiento del PIB regional disminuyó del 6\% al 0,2\%; más aún, el período 2014-2019 fue el de menor crecimiento desde la década de 1950 (0,4\%) (véase el gráfico 1). A medida en que la pandemia se propaga en la región, su caracterización como crisis sanitaria, económica y social es cada vez más evidente. La dimensión y la duración de sus efectos, si bien difíciles de cuantificar debido a la incertidumbre, comienzan a ser percibidas con claridad. Será la causa de la mayor crisis económica y social de la región en décadas, con efectos muy negativos en el empleo, el combate a la pobreza y la reducción de la desigualdad. Dimensionar la caída de la actividad económica permite comenzar a determinar la magnitud del esfuerzo para un regreso a la normalidad. Pero ese regreso no será, y no debe ser, una vuelta a la situación existente antes de la pandemia. Por ello, es necesario hacer también consideraciones de mediano plazo para entender los cambios estructurales en la organización de la actividad productiva que están en proceso y que se intensificarán. Esto además tendrá impactos, en ocasiones irreversibles, en la estructura laboral, el empleo y el bienestar.

- Gráfico 1

América Latina y el Caribe: tasa de crecimiento del PIB real, 1951-2019

(En porcentajes)

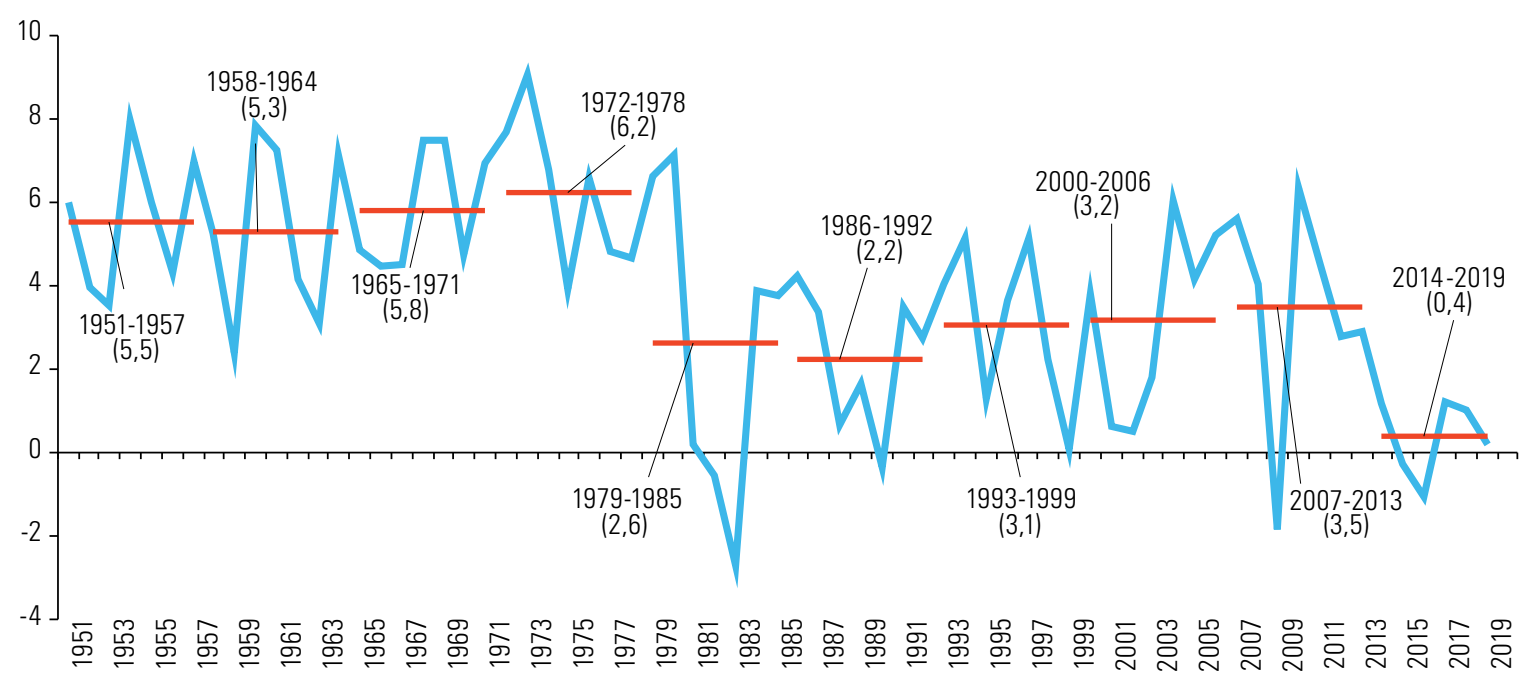

Fuente: Comisión Económica para América Latina y el Caribe (CEPAL), sobre la base de cifras oficiales.

Por otra parte, la acumulación de déficits fiscales en América Latina (2,7\% en promedio en la última década) aumentó la deuda pública bruta de los gobiernos centrales, que, en 2019, promedió un $44,8 \%$ del PIB, un incremento de 15 puntos porcentuales respecto a su mínimo en 2011. Existe gran heterogeneidad entre países, mientras el Paraguay y el Perú tenían niveles de endeudamiento inferiores al $25 \%$ del PIB a finales de 2019, otros países presentaban niveles mucho mayores, que alcanzaban el $89,4 \%$ en la Argentina, el 75,8\% en el Brasil y el 61,3\% en Costa Rica. El peso de la deuda no solo es notorio en los gobiernos centrales, sino también en las empresas públicas no financieras. 
El aumento del pago de intereses redujo los recursos disponibles para el desarrollo, como se evidencia en la evolución del gasto en salud pública e inversiones. El pago de intereses aumentó del 1,7\% del PIB en 2010 al 2,6\% del PIB en 2019 (véase el gráfico 2), mientras que el gasto en salud tuvo un incremento mucho menor (del 1,9\% en 2010 al 2,3\% en 2018). Por su parte, el gasto de capital se redujo del 3,9\% al 3,2\% del PIB y fue la variable de ajuste durante el proceso de consolidación fiscal observado entre 2016 y 2018. Una situación especialmente preocupante en materia de la carga del servicio de la deuda se da en los países centroamericanos y caribeños.

- Gráfico 2

América Latina ( 16 países $^{\mathrm{a}}$ ): pago de intereses, gastos de capital y gasto en salud de gobiernos centrales, 2010-2019b

(En porcentajes del PIB)

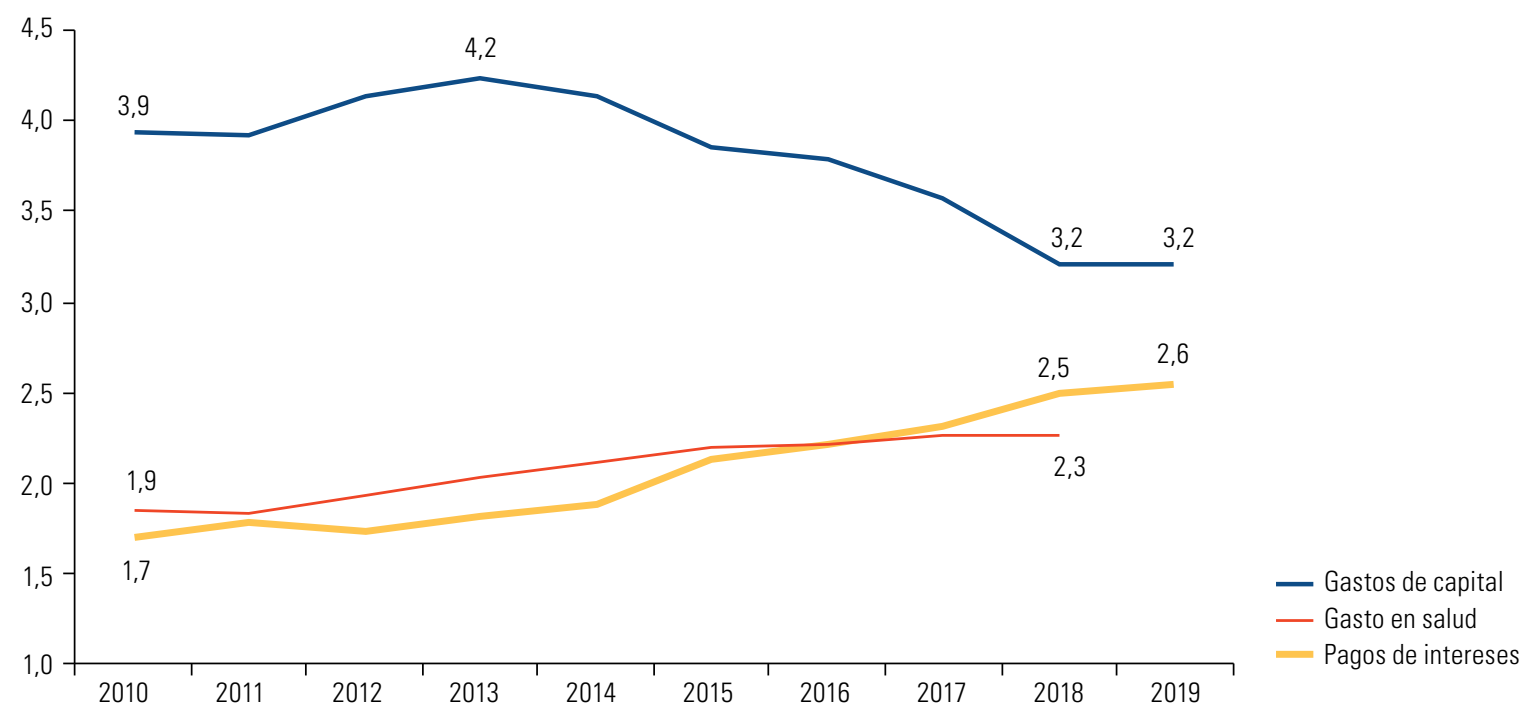

Fuente: Comisión Económica para América Latina y el Caribe (CEPAL), sobre la base de cifras oficiales.

a Incluye los siguientes países: Argentina, Brasil, Chile, Colombia, Costa Rica, Ecuador, El Salvador, Guatemala, Honduras, México, Nicaragua, Panamá,

Paraguay, Perú, República Dominicana y Uruguay.

b Los datos de gasto en salud están disponibles solo hasta 2018.

Pese a que en la última década los países de Centroamérica han buscado reducir la carga de su deuda mediante reformas fiscales (Costa Rica, Honduras) o la generación de superávits primarios (El Salvador), la deuda pública de los gobiernos centrales aumentó de un promedio del 33,2\% del PIB en 2010 a uno del 44,0\% del PIB en 2019; al mismo tiempo, los pagos de intereses crecieron del $1,8 \%$ del PIB al 2,5\% del PIB. Para mantener la sostenibilidad de la deuda pública, se redujeron los gastos de capital para acomodar el aumento de los pagos de intereses, que son mayores que el gasto en áreas como la salud, educación y la protección social. Por ejemplo, el gasto en salud de los gobiernos centrales de El Salvador (2,4\% del PIB), Guatemala $(1,1 \%$ del PIB), Honduras (2,4\% del PIB), Panamá (1,7\% del PIB) o la República Dominicana $(1,7 \%$ del PIB) es menor que los pagos de intereses de la deuda.

Por su parte, los países del Caribe de habla inglesa, debido a su constante necesidad de financiamiento para recuperar su estructura productiva tras los desastres climáticos, presentan un alto endeudamiento público, que se traduce en una marcada carga de los pagos de intereses en las erogaciones públicas. Aunque el resultado primario de sus gobiernos centrales ha sido superavitario en la mayoría de los años durante la última década (con un promedio del 0,8\% del PIB), los balances globales de los gobiernos centrales se han mantenido deficitarios, con un promedio del 2,5\% del PIB. La generación de superávits primarios inhibió el financiamiento para la inversión pública y el gasto social. Aunque los elevados superávits primarios llevaron a una disminución de la deuda pública del 72,8\% del PIB en 2017 al 68,5\% del PIB en 2019, países como Barbados, Belice y Jamaica aún tienen elevados niveles de deuda y, por ende, altos pagos de intereses $(3,4 \%, 2,9 \%$ y $6,3 \%$ del PIB, respectivamente). 
En el conjunto de América Latina y el Caribe, el espacio fiscal es reducido y los ingresos públicos son limitados. Durante la última década, los ingresos públicos totales de los gobiernos centrales de América Latina promediaron el 18,2\% del PIB. Este estancamiento se debió a la ralentización de la actividad económica, la evasión fiscal, la caída de los precios internacionales de las materias primas — que afecta especialmente a América del Sur y a México—, la reducción de aranceles por la apertura comercial y la creciente renuncia fiscal por concesiones a las zonas francas y la maquila. En la coyuntura actual, los ingresos públicos se verán aún más afectados por la fuerte contracción de la actividad económica y los deprimidos precios de las materias primas.

En este cuadro de estrechez fiscal, cuatro conjuntos de problemas relacionados con los sistemas de protección social acentúan los efectos de la pandemia.

i) Altas tasas de informalidad, aumento del trabajo por cuenta propia y brechas en el acceso a la protección social contributiva.

ii) Pocos países cuentan con prestaciones de desempleo; en 2019, solo en ocho países de América Latina y el Caribe los trabajadores del sector formal tenían seguro de desempleo.

iii) Los sistemas de protección social contributiva serán afectados financieramente por la mayor demanda de prestaciones de licencia por enfermedad por parte de los trabajadores del sector formal.

iv) Será necesario ampliar los programas de protección social no contributiva que se financian con impuestos y apoyan a los más pobres a otras familias de bajos ingresos en riesgo de caer en la pobreza.

La crisis sanitaria genera condiciones que exacerban la violencia de género, al tiempo que pone en evidencia la injusta organización social de los cuidados en la región donde se considera una externalidad y no un componente fundamental para el desarrollo. Los niños y las niñas que no pueden asistir a la escuela requieren cuidados que sobrecargan el tiempo de las familias, en particular de las mujeres, quienes dedican diariamente el triple del tiempo al trabajo doméstico y de cuidados no remunerados en comparación con el que dedican los hombres a las mismas tareas. Más aun, las desigualdades de género se acentúan en hogares de menores ingresos donde las demandas de cuidados son mayores al tener más dependientes por hogar.

También la presión sobre los sistemas de salud afecta significativamente a las mujeres ya que representan más del $70 \%$ del total de personas ocupadas en este sector en la región. El aumento de demanda en los sistemas de salud ha mostrado condiciones de trabajo extremas, como extensas jornadas laborales sin descanso o pausas para comer o ir al baño, que se suman al riesgo de que el personal de la salud está más expuesto al contagio del virus. A su vez, las mujeres que trabajan en este sector no dejan por ello de tener a su cargo personas dependientes o que necesitan cuidados en sus hogares. Deben seguir asistiendo a sus trabajos con esta responsabilidad, lo que aumenta sus sobrecargas de trabajo y estrés.

\section{B. La pandemia llevará a la mayor contracción de la actividad económica en la historia de la región}

La pandemia impacta a las economías de América Latina y el Caribe a través de factores externos e internos cuyo efecto conjunto conducirá a la peor contracción que la región ha sufrido desde que se inician los registros, en 1900.

La economía mundial exhibirá en 2020 una caída del producto bruto mayor a la observada en varias décadas. Se prevé una contracción del PIB mundial en torno al $2 \%$ con una mayor contracción en las economías desarrolladas que en las emergentes. A fines de abril, las proyecciones para los Estados Unidos prevén una caída de casi el 4\% (frente a un crecimiento del 1,9\% pronosticado en diciembre de 2019), para China un crecimiento menor al $2 \%$ (5,8\% pronosticado en diciembre), 
para la eurozona una caída de casi el $6 \%(1,2 \%$ de crecimiento pronosticado en diciembre) y para el Japón una contracción de más del $4 \%$ (véase el cuadro 1).

\section{- Cuadro 1}

Regiones y países seleccionados: tasa de crecimiento del PIB 2013-2019 y proyecciones 2020

(En porcentajes)

\begin{tabular}{|c|c|c|c|c|c|c|c|c|}
\hline & 2013 & 2014 & 2015 & 2016 & 2017 & 2018 & 2019 & 2020 \\
\hline Mundo & 2,6 & 2,8 & 2,8 & 2,6 & 3,2 & 3,1 & 2,4 & $-2,0$ \\
\hline Estados Unidos & 1,8 & 2,5 & 2,9 & 1,6 & 2,4 & 2,9 & 2,3 & $-3,8$ \\
\hline Japón & 2,0 & 0,4 & 1,3 & 0,6 & 2,0 & 0,8 & 0,7 & $-4,2$ \\
\hline Eurozona & $-0,3$ & 1,4 & 2,1 & 1,9 & 2,5 & 1,9 & 1,2 & $-5,7$ \\
\hline China & 7,8 & 7,3 & 6,9 & 6,7 & 6,9 & 6,6 & 6,1 & 1,8 \\
\hline India ${ }^{a}$ & 6,4 & 7,4 & 8,0 & 8,2 & 7,2 & 6,8 & 5,8 & 3,4 \\
\hline
\end{tabular}

Fuente: Comisión Económica para América Latina y el Caribe (CEPAL), sobre la base de Instituto de Finanzas Internacionales (IIF), Capital Flows Report: Sudden Stop in Emerging Markets, 9 de abril de 2020; y datos de Bloomberg.

a Las cifras de la India corresponden al año fiscal, que comienza en abril y termina en marzo del año siguiente.

El volumen de comercio mundial se ha reducido drásticamente: la Organización Mundial del Comercio (OMC, 2020) estima que caerá entre el $13 \%$ y el $32 \%$ en 2020 . El volumen de comercio mundial de bienes presentaba una tendencia negativa antes de la pandemia. En 2019 disminuyó un $0,4 \%$, su primera caída desde la crisis financiera mundial (véase el gráfico 3). Esto fue en gran medida el resultado de la acumulación de barreras comerciales desde principios de 2018 (principalmente entre los Estados Unidos y China) y su efecto en las cadenas globales de valor. Las perspectivas mejoraron en enero de 2020 luego del acuerdo de "fase uno" entre China y los Estados Unidos, pero la pandemia puso fin a ese corto optimismo. A la disrupción de las cadenas de valor, se agrega el hecho de que China, una vez que comience a reactivar su producción, tendrá problemas para exportar a países que enfrentan la pandemia con un rezago temporal respecto de este país. Así, uno de los principales actores en el comercio mundial verá disminuida la demanda de sus exportaciones, lo que aumentará el impacto negativo sobre el volumen mundial de comercio.

\section{- Gráfico 3}

\section{Tasa de variación interanual del volumen del comercio mundial de bienes}

(En porcentajes, sobre la base de un índice desestacionalizado)

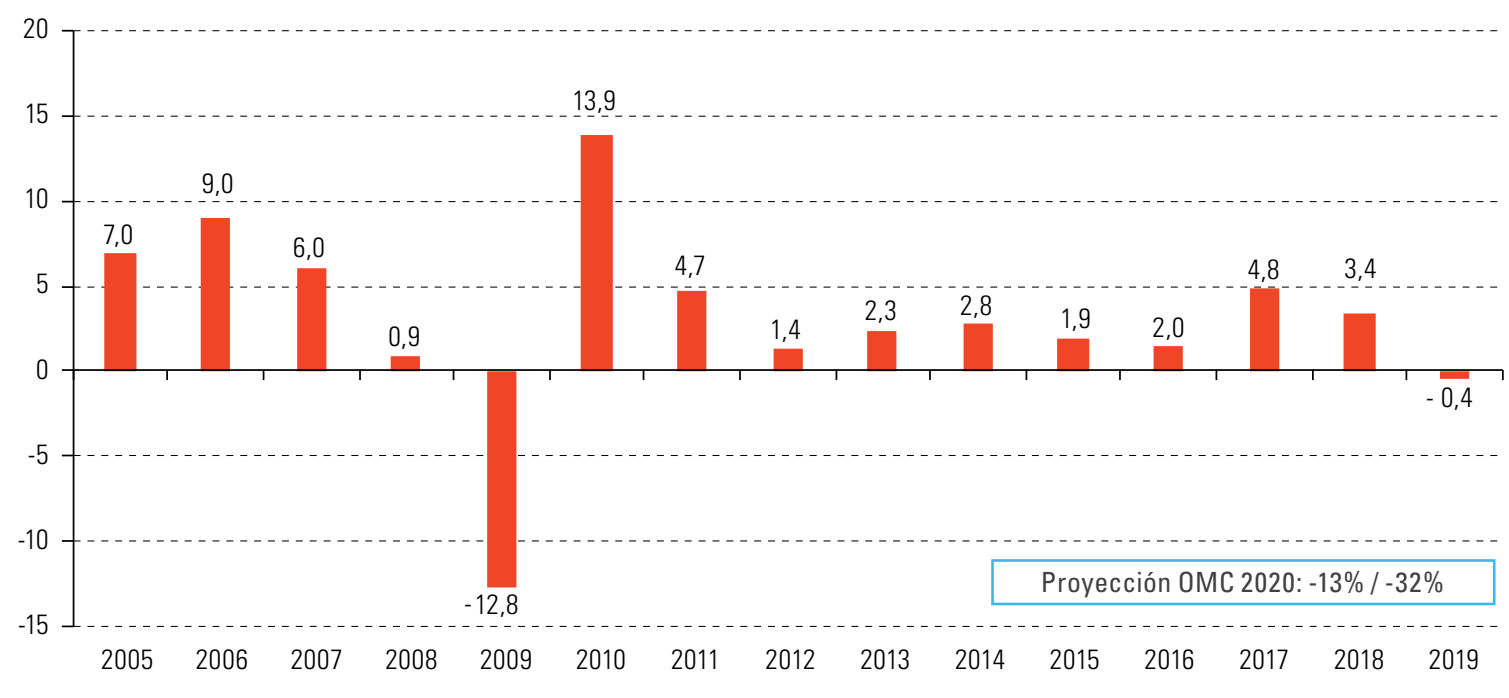

Fuente: Comisión Económica para América Latina y el Caribe (CEPAL), sobre la base de Netherlands Bureau of Economic Policy Analysis (CPB), World Trade Monitor [base de datos en línea] https://www.cpb.nl/en/worldtrademonitor; Organización Mundial del Comercio (OMC), “Trade forecast press conference", 8 de abril de 2020 [en línea] https://www.wto.org/english/news_e/spra_e/spra303_e.htm. 
La caída de la actividad económica mundial, en particular en los Estados Unidos, China y Europa, tiene un impacto negativo en América Latina y el Caribe a través del comercio, en sus dimensiones de volumen y precio, en especial de materias primas. Algunos importantes sectores productivos de países de la región están insertos en cadenas globales de valor en las que los Estados Unidos y China juegan un papel fundamental. Además, México y Centroamérica están expuestos a la contracción de la economía de los Estados Unidos también a través la reducción de las remesas de los migrantes; en el caso de México se agrega la caída del precio del petróleo. Ante el nuevo panorama económico de los principales socios de la región y una acentuación del desplome de los precios de exportación, el valor de las exportaciones de la región caería cerca del 15\%, con una disminución de los precios del 8,8\% y una contracción del volumen del 6\%, que obedece principalmente a una agudización de la contracción de la demanda mundial (véase el cuadro 2).

- Cuadro 2

América Latina y el Caribe: efectos del COVID-19 en las exportaciones de bienes por subregiones y paises de exportación principales, pronóstico para $2020^{a}$

(Variación porcentual)

\begin{tabular}{lccc} 
Región/Subregión/Pais & Volumen & Precio & Valor \\
\hline América Latina y el Caribe & $-6,0$ & $-8,8$ & $-14,8$ \\
\hline Exportadores de petróleo & $-4,7$ & $-14,6$ & $-19,2$ \\
\hline Exportadores de minerales & $-7,4$ & $-9,3$ & $-16,7$ \\
\hline Exportadores de productos agroindustriales & $-6,2$ & $-4,0$ & $-10,2$ \\
\hline América del Sur & $-6,0$ & $-11,6$ & $-17,6$ \\
\hline Brasil & $-7,0$ & $-8,1$ & $-15,1$ \\
\hline México & $-6,0$ & $-5,7$ & $-11,6$ \\
\hline Centroamérica & $-4,9$ & $-5,3$ & $-10,3$ \\
\hline Países del Caribe & $-6,2$ & $-7,7$ & $-13,9$ \\
\hline
\end{tabular}

Fuente: Comisión Económica para América Latina y el Caribe (CEPAL).

a Se asumen las siguientes tasas de crecimiento para 2020: -2,0\% (mundial), -3,8\% (Estados Unidos), -4,2\% (Japón), -5,7\% (Unión Europea, 27 países), 1,8\% (China) y -5,3\% (América Latina y el Caribe), más una reducción media del 18\% en la cesta de exportación de productos primarios de la región.

Se prevé que, en promedio, los bajos precios se prolonguen en el tiempo, incluso para productos que no habían experimentado disminuciones. Por ejemplo, recientemente, la cotización de los precios de los productos agrícolas que no habían caído tanto como el petróleo y los metales han comenzado a disminuir debido a la contracción de la demanda. Los precios de la soja, el maíz, y el trigo se redujeron hasta un $4 \%$ y los precios de la carne de bovino y pollo disminuyeron un $6 \%$ en el último bimestre. En el caso del petróleo, principal producto de exportación de la región, la importante merma de la demanda, estimada en un 30\%, no podrá ser compensada por el último acuerdo de la Organización de Países Exportadores de Petróleo (OPEP) que recorta la producción de los países miembros de la organización un 20\% (hasta 9,7 millones de barriles diarios).

Las mayores repercusiones se observarían en los países de América del Sur, que se especializan en la exportación de bienes primarios y, por lo tanto, son más vulnerables a la disminución de sus precios. Por su parte, el valor de las exportaciones de Centroamérica, el Caribe y México sufrirá el efecto de la desaceleración de la economía de los Estados Unidos. Como se mencionó, México sufrirá además un fuerte impacto por la caída del precio del petróleo. Las exportaciones regionales a China serían las que más disminuirían en 2020 (24,4\%). Esto afectaría especialmente a los productos con eslabonamientos hacia adelante en las cadenas de valor en ese país (mineral de hierro, mineral de cobre, zinc, aluminio, soja, aceite de soja, entre otros). Los países más expuestos son la Argentina, el Brasil, Chile y el Perú, los mayores exportadores de la región de esos productos a China.

Las condiciones financieras a nivel mundial sufrieron un deterioro comparable -incluso mayor en algunos indicadores- al observado durante la crisis financiera mundial de 2008-2009. 
La volatilidad aumentó a niveles históricos, se produjeron salidas masivas de capitales desde los mercados emergentes, una depreciación de la mayor parte de las monedas respecto del dólar y considerables aumentos en los niveles de riesgo soberano, excepto en los países considerados como refugio, a los que "huyen" los inversores en busca de seguridad, y donde, por el contrario, alcanzaron mínimos históricos. Los mercados bursátiles de todo el mundo sufrieron fuertes caídas reflejo de la preocupación por los efectos de la pandemia en la situación financiera de las empresas.

El hecho de que los mercados financieros se hayan visto gravemente afectados por el efecto de la pandemia mundial es producto también de las vulnerabilidades financieras que se habían ido acumulando durante mucho tiempo. La acumulación de deuda ha superado el crecimiento del ingreso mundial y ha alcanzado niveles récord. En el cuarto trimestre de 2019, el acervo de deuda global superó los 255 billones de dólares, más de 322\% del PIB mundial (IFF, 2020a).

El aumento de la deuda fue acompañado por estándares de préstamos más laxos y mayor aceptación de riesgo por parte de los inversores en busca de rendimiento. Si bien el aumento de la deuda se produjo en todos los sectores (hogares, sector corporativo no financiero, gobierno y sector financiero), lo que ahora genera serias preocupaciones es que gran parte de la acumulación de deuda desde la crisis financiera mundial se ha dado en sector corporativo no financiero, donde la interrupción de las cadenas de suministro y la reducción del crecimiento mundial implican menores ganancias y una mayor dificultad en el servicio de la deuda. La recesión afecta la capacidad de los prestatarios corporativos de obtener ganancias y pagar deudas, lo que se agrava por el aumento en los costos de endeudamiento y las interrupciones en la capacidad de financiamiento que enfrentan esos prestatarios.

En América Latina, la menor disponibilidad de flujos de financiación hacia economías emergentes se traduce en una ralentización de los flujos de capitales del exterior (una disminución de casi 80.000 millones de dólares respecto de 2019) y salidas netas en los flujos de cartera y otra inversión por parte de no residentes (IFF, 2020b). Los flujos de remesas hacia América Latina y el Caribe se podrían contraer entre un 10\% y un $15 \%$ en 2020 y podrían pasar entre 4 y 8 años para que regresen al monto alcanzado en 2019. En varios países de la región la contribución de este flujo a la actividad económica es muy significativa. En Haití representó más del 30\% del PIB, en El Salvador y Honduras se ubicó en torno al $20 \%$, y en Jamaica, Guatemala y Nicaragua su peso fue superior al $10 \%$. Entre un $80 \%$ y un $90 \%$ de las remesas se emplean para cubrir necesidades básicas de los hogares receptores (alimentación, salud y vivienda), por lo que su contracción tendrá fuertes efectos en el consumo y la incidencia de la pobreza.

En el principal país de destino de los migrantes de la región (Estados Unidos), la crisis sanitaria afecta a sectores en los que estos tradicionalmente se emplean, como la construcción, los restaurantes y los hoteles. En 2018, el 28,7\% de los migrantes provenientes de los países de la región se empleaban en servicios y el 20,6\% en construcción y mantenimiento (Oficina del Censo de los Estados Unidos, 2018). El impacto de la crisis en las remesas podría verse atenuado por los apoyos directos (transferencias) que reciban los migrantes en los lugares de destino y las familias receptoras en las comunidades de origen. La crisis también ha puesto de manifiesto los aportes de la fuerza laboral inmigrante en sectores como la producción de alimentos y los servicios de salud en estados donde tienen una presencia considerable.

El turismo es uno de los sectores más afectados y su recuperación depende de la apertura de las fronteras a nivel mundial. En 2020 se registraría una reducción de entre un 20\% y un 30\% en el número de llegadas de turistas en el mundo, una caída mucho mayor que la observada en 2009 (4\%) (OMT, 2020). En un escenario en el que los ingresos del turismo disminuyeran un $30 \%$ en 2020, el PIB se reduciría 2,5, 0,8 y 0,3 puntos porcentuales en el Caribe, México y Centroamérica, y América del Sur, respectivamente. Las repercusiones en el empleo, los ingresos de los hogares y los ingresos gubernamentales serían mayores en el Caribe, donde ese sector emplea a unos 2,4 millones de personas y representa el 15,5\% del PIB. Los efectos de la retracción del turismo se sentirán en particular en las micro y pequeñas empresas, cuyo peso en el sector de hoteles y restaurantes es muy grande: el $99 \%$ de las empresas y el $77 \%$ del empleo. 
Al choque externo se suman fuertes choques internos en la medida en que las políticas de contención sanitaria para prevenir la propagación de la pandemia conducen a una paralización de la producción y la actividad económica. Ante la inexistencia de tratamientos y vacunas para enfrentar al virus, los esfuerzos para controlar la pandemia se centran en restricciones a la circulación de individuos, lo que afecta la actividad productiva en diferente medida según cada sector. Las cuarentenas y el aislamiento social significaron fuertes caídas en actividades como la aviación, el turismo, el comercio y las zonas francas. Las empresas, independientemente de su tamaño, enfrentan importantes disminuciones de sus ingresos, dificultades para el acceso al crédito y un aumento en la probabilidad de insolvencia. Además, los trabajadores sufren un marcado deterioro en las condiciones laborales, empleo o ingresos que, sumado a lo anterior, lleva a un deterioro en la demanda agregada de los países y a aumentos en la pobreza.

\section{La economía de los países de América Latina y el Caribe en 2020: la CEPAL proyecta una contracción de la actividad del $5,3 \%$ y casi 30 millones más de pobres}

Se prevé una caída del 5,2\% en la actividad económica de América del Sur. Algunos países de esta subregión se ven muy afectados por la disminución de la actividad en China, un importante mercado para sus exportaciones de bienes. Es el caso, por ejemplo, del Brasil, Chile, el Perú y el Uruguay, que destinan a China más del $20 \%$ de sus exportaciones (más del $30 \%$ en el caso de Chile). América del Sur se verá afectada también por la disminución de los precios de los productos básicos.

La interrupción de las cadenas de valor repercutirá con mayor intensidad en las economías brasileña y mexicana, cuyos sectores manufactureros son los mayores de la región. Para el Brasil, se prevé una caída del 5,2\% y para México una caída del 6,5\%. Para las economías de Centroamérica, se espera una caída menor (2,3\%). La reducción de los precios de los productos básicos no sería un problema ya que son importadoras netas de alimentos y energía. Sin embargo, sí tienen fuertes efectos negativos la marcada disminución del turismo y la merma de la actividad de los Estados Unidos, principal socio comercial y la mayor fuente de inversión extranjera directa y remesas de los países de la subregión. Las economías del Caribe tendrían una caída del 2,5\%, consecuencia, principalmente, de la reducción de la demanda de servicios turísticos, que son intensivos en trabajo.

Las proyecciones también anticipan un importante deterioro de los indicadores laborales en 2020. La tasa de desempleo se ubicaría en torno al 11,5\%, un aumento de 3,4 puntos porcentuales con respecto al nivel de 2019 (8,1\%). Así, el número de desempleados de la región llegaría a 37,7 millones, lo que implicaría un aumento cercano a 11,6 millones con respecto al nivel de 2019 (26,1 millones de desempleados). Estas proyecciones suponen que el número de ocupados caería cerca del 2,4\%, con respecto al nivel de 2019. Los países del Caribe sufrirían una caída mayor debido a que, en muchos de ellos, el sector del turismo es fuente de más del $50 \%$ del empleo. Estos números son significativamente mayores que los observados durante la crisis financiera mundial, cuando la tasa de desempleo de la región se incrementó 0,6 puntos porcentuales en 2009 (al $7,3 \%$, en comparación con el 6,7\% en 2008). La alta tasa de informalidad laboral de la región hace muy vulnerables a los trabajadores a los efectos de la pandemia y a las medidas para enfrentarla. La elevada participación de las pequeñas y medianas empresas en la creación del empleo (más del $50 \%$ del empleo formal) aumenta los efectos negativos, pues este sector ha sido duramente afectado por la crisis. La desigualdad de género se acentuará por medidas como el cierre de las escuelas, el aislamiento social y el aumento del número de personas enfermas, pues aumentará la sobrecarga de trabajo no remunerado de las mujeres. 
- Cuadro 3

Proyecciones de crecimiento del PIB en 2020

\begin{tabular}{|c|c|}
\hline & $\begin{array}{l}\text { Crecimiento del PIB } \\
2020\end{array}$ \\
\hline América Latina y el Caribe & $-5,3 \%$ \\
\hline Argentina & $-6,5 \%$ \\
\hline Bolivia (Estado Plurinacional de) & $-3 \%$ \\
\hline Brasil & $-5,2 \%$ \\
\hline Chile & $-4 \%$ \\
\hline Colombia & $-2,6 \%$ \\
\hline Ecuador & $-6,5 \%$ \\
\hline Paraguay & $-1,5 \%$ \\
\hline Perú & $-4 \%$ \\
\hline Uruguay & $-4 \%$ \\
\hline Venezuela (República Bolivariana de) & $-18 \%$ \\
\hline América del Sur & $-5,2 \%$ \\
\hline Costa Rica & $-3,6 \%$ \\
\hline Cuba & $-3,7 \%$ \\
\hline El Salvador & $-3 \%$ \\
\hline Guatemala & $-1,3 \%$ \\
\hline Haití & $-3,1 \%$ \\
\hline Honduras & $-2,8 \%$ \\
\hline México & $-6,5 \%$ \\
\hline Nicaragua & $-5,9 \%$ \\
\hline Panamá & $-2 \%$ \\
\hline República Dominicana & $0 \%$ \\
\hline Centroamérica y México & $-5,5 \%$ \\
\hline Centroamérica & $-2,3 \%$ \\
\hline América Latina & $-5,3 \%$ \\
\hline Antigua y Barbuda & $-7,2 \%$ \\
\hline Bahamas & $-6,8 \%$ \\
\hline Barbados & $-5,8 \%$ \\
\hline Belice & $-3,9 \%$ \\
\hline Dominica & $-3,6 \%$ \\
\hline Granada & $-7,3 \%$ \\
\hline Guyana & $56,4 \%$ \\
\hline Jamaica & $-5,3 \%$ \\
\hline Saint Kitts y Nevis & $-6,5 \%$ \\
\hline San Vicente y las Granadinas & $-3,6 \%$ \\
\hline Santa Lucía & $-8,1 \%$ \\
\hline Suriname & $-4,4 \%$ \\
\hline Trinidad y Tabago & $-5 \%$ \\
\hline El Caribe & $-2,5 \%$ \\
\hline
\end{tabular}

Fuente: Comisión Económica para América Latina y el Caribe (CEPAL).

Nota: En este análisis, Centroamérica incluye a Cuba, Haití y la República Dominicana.

La caída del 5,3\% del PIB y el aumento de 3,4 puntos porcentuales del desempleo tendrían un efecto negativo directo sobre los ingresos de los hogares y su posibilidad de contar con recursos suficientes para satisfacer las necesidades básicas. En ese contexto, la tasa de pobreza aumentaría 4,4 puntos porcentuales durante 2020 al pasar del 30,3\% al 34,7\%, lo que significa un incremento 
de 28,7 millones de personas en situación de pobreza (véase el cuadro 4). Por su parte, la pobreza extrema crecería 2,5 puntos porcentuales, pasando del $11,0 \%$ al $13,5 \%$, lo que representa un incremento de 16 millones de personas.

También se deteriorará la distribución del ingreso. Solo el aumento del desempleo resultaría en un incremento del índice de Gini de entre un 1\% y un 2\%, sin considerar el aumento adicional provocado por una caída en los ingresos del empleo que afecte en mayor medida a los hogares de menores recursos.

- Cuadro 4

América Latina: pobreza y extrema pobreza en un escenario de caída del PIB del $5,3 \%$ y de aumento del desempleo en 3,4 puntos porcentuales en 2020

(En millones de personas y porcentajes)

\begin{tabular}{lccc} 
Año & $\mathbf{2 0 1 8}$ & $\mathbf{2 0 1 9}$ & $\mathbf{2 0 2 0 ^ { 2 }}$ \\
Población & 607,7 & 613,5 & 619,2 \\
\hline Pobreza & & & \\
\hline América Latina (18 paises) & 180,6 & 186,0 & 214,7 \\
\hline Tasa & $29,7 \%$ & $30,3 \%$ & $34,7 \%$ \\
\hline Pobreza extrema & & & \\
\hline América Latina(18 paises) & 62,5 & 67,5 & 83,4 \\
Tasa & $10,3 \%$ & $11,0 \%$ & $13,5 \%$ \\
\hline
\end{tabular}

Fuente: Comisión Económica para América Latina y el Caribe (CEPAL).

a Estas estimaciones son preliminares y no toman en consideración el impacto diversificado entre los sectores productivos y el empleo generado en cada uno de ellos. 

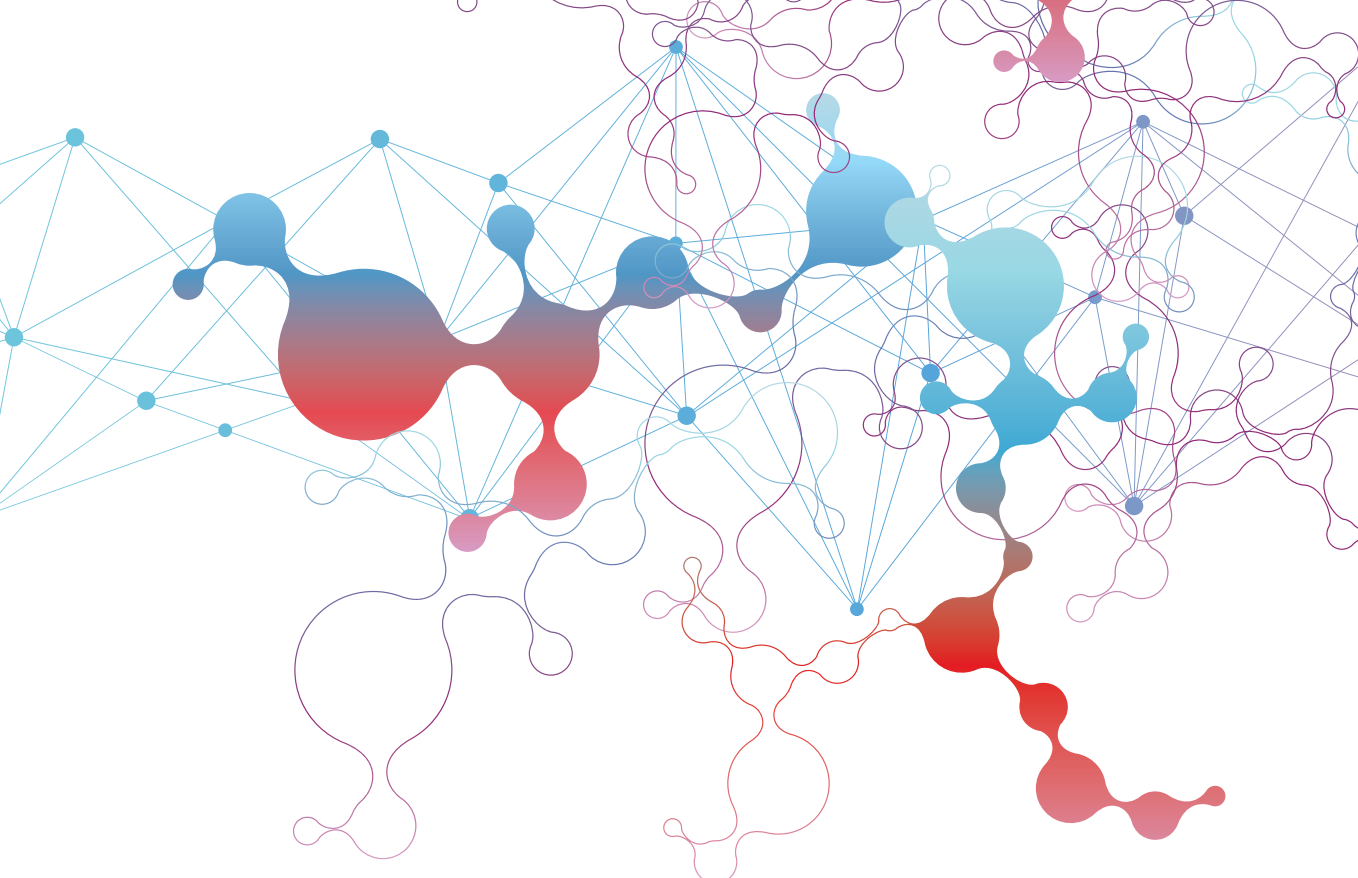


\section{Geoportal COVID-19: difusión y seguimiento de las acciones para enfrentar la pandemia}

La CEPAL ha implementado un geoportal, integrado en el Observatorio COVID-19 en América Latina y el Caribe, que proporciona acceso a la información sobre las acciones implementadas por los países de la región para enfrentar la pandemia. Esta información está desagregada por tipo de medida: restricciones de movimientos, salud, economía, trabajo, protección social y educación, y próximamente se incluirán las acciones relacionadas con la dimensión de género. Esta herramienta facilita la difusión y el intercambio de experiencias dentro de la región para que los países fortalezcan su gestión de la pandemia. Las imágenes 1, 2 y 3 muestran ejemplos de los resultados ofrecidos por el portal.

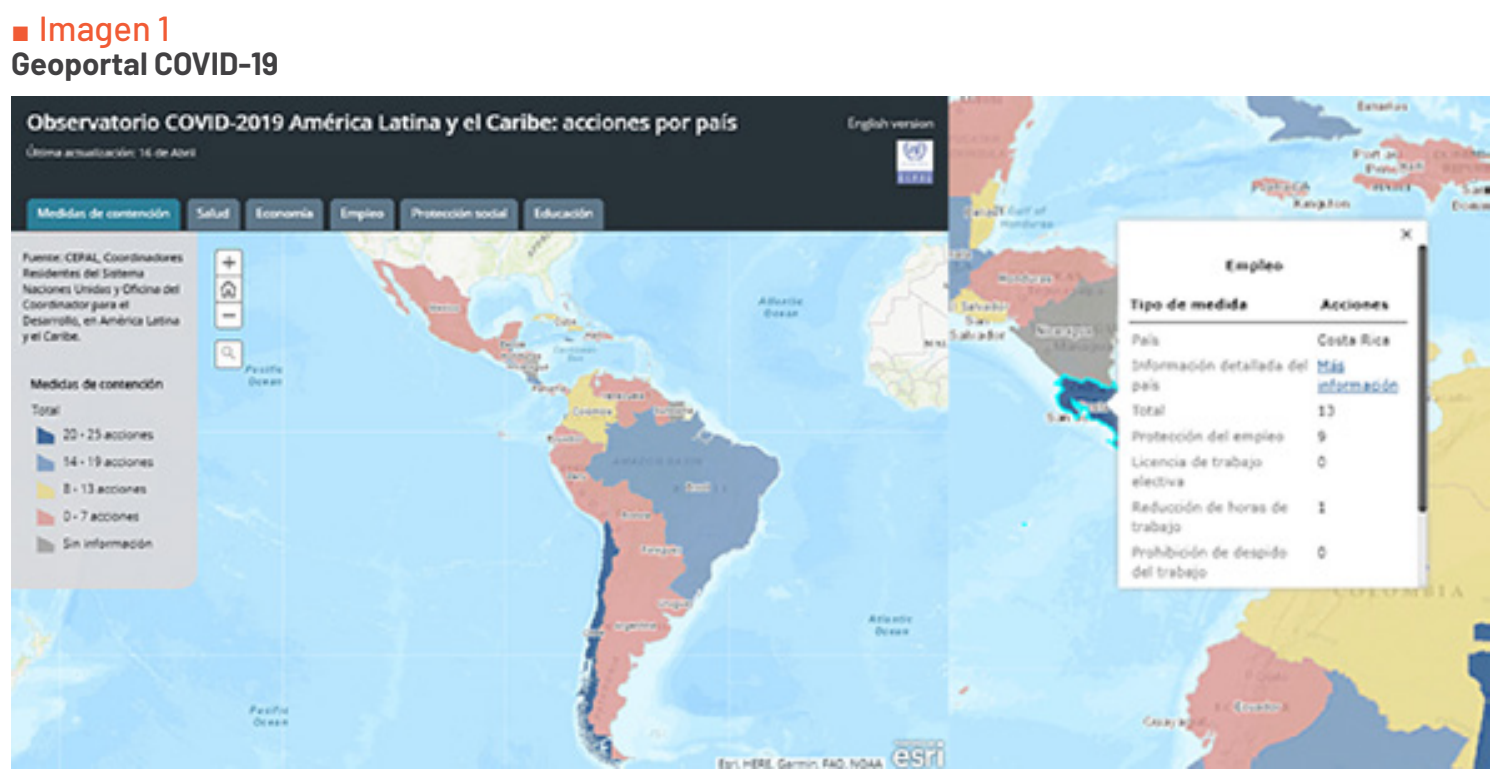

Fuente: Comisión Económica para América Latina y el Caribe (CEPAL), Observatorio COVID-19 en América Latina y el Caribe: Impacto Económico y Social [en línea] https://www.cepal.org/es/temas/covid-19.

El geoportal proporciona información sobre la fecha en que se tomaron las medidas y acciones, así como detalles sobre ellas, y la organización gubernamental a cargo. El flujo de datos comienza en cada país que recaba y registra información sobre estas medidas y acciones anunciadas por el gobierno. Una vez recibidos en la sede de la CEPAL, los datos se compilan en una base centralizada, se complementan con datos de las bases permanentes de la institución y, finalmente, se cargan en el geoportal. Hay un esfuerzo continuo para mejorar las funcionalidades y automatizar los procesos de administración de esta herramienta. 
- Imagen 2

América Latina y el Caribe (31 países): número de acciones tomadas semanalmente por los gobiernos para limitar el impacto de la pandemia, al 22 de abril de 2020

\begin{tabular}{|c|c|c|c|c|c|c|c|c|c|c|c|c|c|c|c|c|c|c|}
\hline & 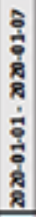 & 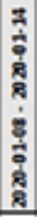 & 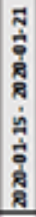 & 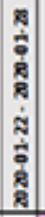 & 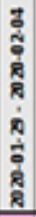 & 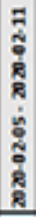 & 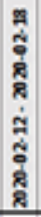 & 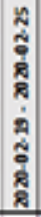 & 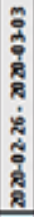 & 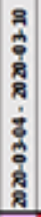 & 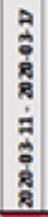 & 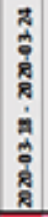 & 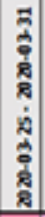 & 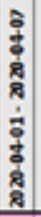 & 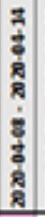 & 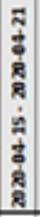 & 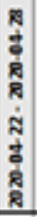 & $\begin{array}{l}8 \\
8 \\
8 \\
8 \\
8 \\
\dot{8} \\
0 \\
\text { i } \\
8 \\
8 \\
8\end{array}$ \\
\hline A. Restrucciones de movimientos & 1 & & & & 7 & 1 & & & 1 & 6 & 86 & 76 & 27 & 12 & 7 & & & \\
\hline 1. Restrictiones o prohibiciones a ia entrada de viajeros extranjeros & & & & & 2 & 1 & & & & 2 & 22 & 17 & s & 1 & & & & \\
\hline 2. Cierres y controles fronterizos & 1 & & & & 4 & & & & 1 & 1 & 22 & 19 & 1 & 1 & & & & \\
\hline 3. Controles fronterizos & & & & & 1 & & & & & & 17 & 6 & 2 & & 1 & & & \\
\hline 4. Restricción o cierre de lugares públicos y reuniones masivas & & & & & & & & & & 1 & 23 & 29 & 15 & , & 2 & & & \\
\hline 5. Otros movimientos a traves y dentro de los paises & & & & & & & & & & & 2 & 5 & 4 & 3 & 4 & & & \\
\hline B. Salud & & & 1 & 3 & 6 & 3 & 1 & 3. & 5 & 5 & 72 & 63 & 24 & 18 & 10 & & & \\
\hline 1. Emergencia de salud & & & 1 & 3 & 1 & 1 & & & 4 & 1 & 17 & 9 & 2 & 1 & 1 & & & \\
\hline 2. Cobertura obligatoria & & & & & & & & & & & 4 & 3 & 1 & & & & & \\
\hline 3. Cuarentena obligatoria para viajeros extranjeros, casos confitmados o sospechosos & & & & & 2 & & & & & 1 & 21 & 9 & 1 & & & & & \\
\hline 4. Cuarentena general oblicatoria & & & & & 2 & 2 & & & & & 10 & 19 & 7 & 2 & 2 & & & \\
\hline 5. Tipo de politica para tomar una prueba & & & & & 2 & & & 3 & 1 & 2 & 6 & 11 & 3 & 1 & & & & \\
\hline 6. Expansión de cobertura de prueba gratuita & & & & & & & 1 & & & & 4 & 6 & 2 & 1 & & & & \\
\hline 7. Hospitales & & & & & & 2 & & & & & 5 & s & 2 & 7 & 2 & & & \\
\hline 8. Otros en Salud & & & & & & & & & & 1 & 5 & 6 & 6 & 6 & 4 & & & \\
\hline C. Economis & & & & & 1 & 1 & & & & 3 & 68 & 156 & 34 & 17 & 11 & & & \\
\hline 1. Politica fiscal & & & & & & & & & & 2 & 11 & 28 & 10 & 10 & 1 & & & \\
\hline 2. Politica monetaria & & & & & & & & & & & ar & 29 & 4 & 2 & 2 & & & \\
\hline 3. Politica de empresas & & & & & 2 & & & & & & 11 & 46 & 11 & 5 & 3 & & & \\
\hline 4. Restrictión de la actividad económica & & & & & & & & & & 1 & 11 & 22 & 4 & & & & & \\
\hline 5. Controles de precios y cantidades & & & & & & & & & & & 7 & 10 & 1 & & 1 & & & \\
\hline 6. Estimule económice & & & & & & & & & & & 3 & 5 & 1 & & 2 & & & \\
\hline 7. Reculación del mercado de hiciene personal y productos de limpieza & & & & & & 2 & & & & & 9 & 5 & 3 & 1 & & & & \\
\hline 8. Alivio de la deuda y suspensión de pazos de crédito & & & & & & & & & & & & 1 & & & 2 & & & \\
\hline 9. Otros en Lconomia & & & & & & & & & & & 3 & 10 & & & 1 & & & \\
\hline D. Emplee & & & & & & & 1 & & & 3 & 44 & 54 & 11 & 10 & 1 & & & 1 \\
\hline 1. Protección del empleo & & & & & & & 1 & & & 3 & 25 & 37 & 7 & 9 & 1 & & & \\
\hline 2. Permiso de trabajo remunerado & & & & & & & & & & & s & 2 & & 2 & & & & \\
\hline 3. Reduccion de horas de trabajo & & & & & & & & & & & 6 & 7 & 1 & & & & & \\
\hline 4. Prohibición de despido del trabajo & & & & & & & & & & & 3 & 4 & & & & & & 1 \\
\hline 5. Otros en Empleo & & & & & & & & & & & 5 & 5 & 3 & & & & & \\
\hline E. Protección social & & & & & 1 & & & & & & 15 & 17 & 10 & 9 & 6 & & & \\
\hline 1. Transferencias de efectivo & & & & & 1 & & & & & & 15 & 12 & 7 & 3 & 3 & & & \\
\hline 2. Transferencias de alimentos / Transferencias en especie & & & & & & & & & & & & 1 & 2 & 1 & 1 & & & \\
\hline 3. Garantia de servicios básicos & & & & & & & & & & & & 4 & & 3 & 2 & & & \\
\hline 4. Otros en Prosecesión social & & & & & & & & & & & & & 1 & 2 & & & & \\
\hline F. Educación/Escuelas & & & & & & & & & & 3 & 39 & 26 & 4 & 7 & & & & \\
\hline 1. Suspensión de clases & & & & & & & & & & 2 & 23 & 10 & 3 & 3 & & & & \\
\hline 2. Dar instrumentos para desarrollar el aprendizaje a distancia & & & & & & & & & & 2 & 14 & 11 & & 2 & & & & \\
\hline 3. Mantener programa de alimentación escolar & & & & & & & & & & & & 2 & & 3 & & & & \\
\hline 4. Otros Educación/Escuelas & & & & & & & & & & & 2 & 3 & 1 & & & & & \\
\hline G. Otres & & & & & & & & & & 3 & 1 & 4 & - & 1 & & & & \\
\hline TOTAL & 1 & & 1 & 3 & 15 & 5 & 2 & 3 & 6 & 23 & 325 & 401 & 110 & 74 & 35 & & & 1 \\
\hline
\end{tabular}

Fuente: Comisión Económica para América Latina y el Caribe (CEPAL). 
- Imagen 3

América Latina y el Caribe (31 países): proporción de países que han implementado tipos específicos de medidas para limitar el impacto de la pandemia, al 22 de abril de 2020

(En porcentajes)

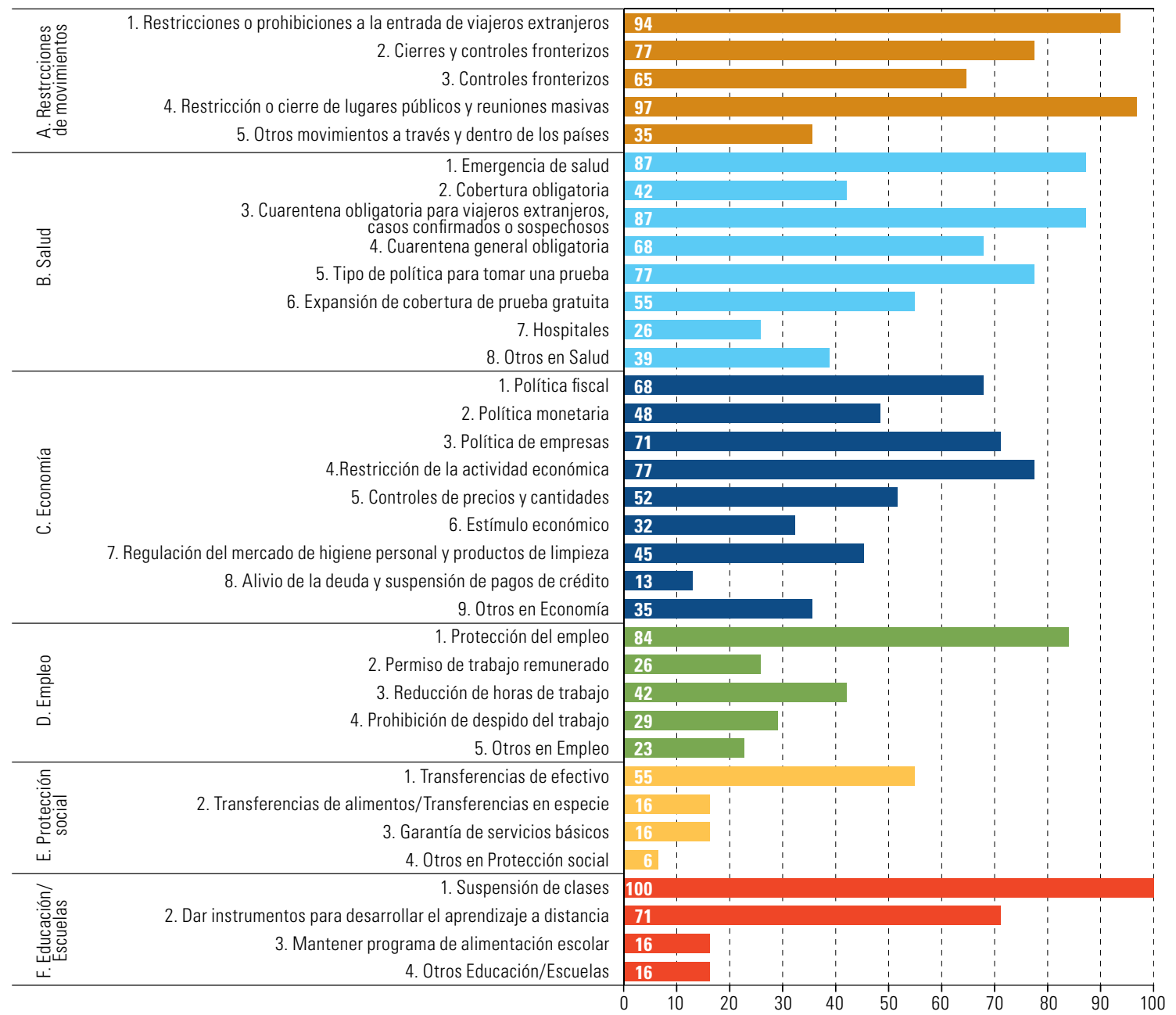

Fuente: Comisión Económica para América Latina y el Caribe (CEPAL).

\section{B. Red de Transmisión del Conocimiento de la Conferencia Estadística de las Américas de la CEPAL: ideas y recomendaciones sobre la continuidad de las principales operaciones estadísticas durante la pandemia}

La Red deTransmisión del Conocimiento (RTC) es un espacio destinado al fortalecimiento del saber y la cooperación en el ámbito de las estadísticas en América Latina y el Caribe. Permite compartir ideas y recomendaciones entre las oficinas nacionales de estadística y otros actores de los sistemas estadísticos nacionales, en particular sobre la continuidad de las principales operaciones estadísticas durante la pandemia (véase la imagen 4). 
- Imagen 4

Ejemplo de plan de contingencia y recomendaciones para la producción estadística frente a la emergencia sanitaria
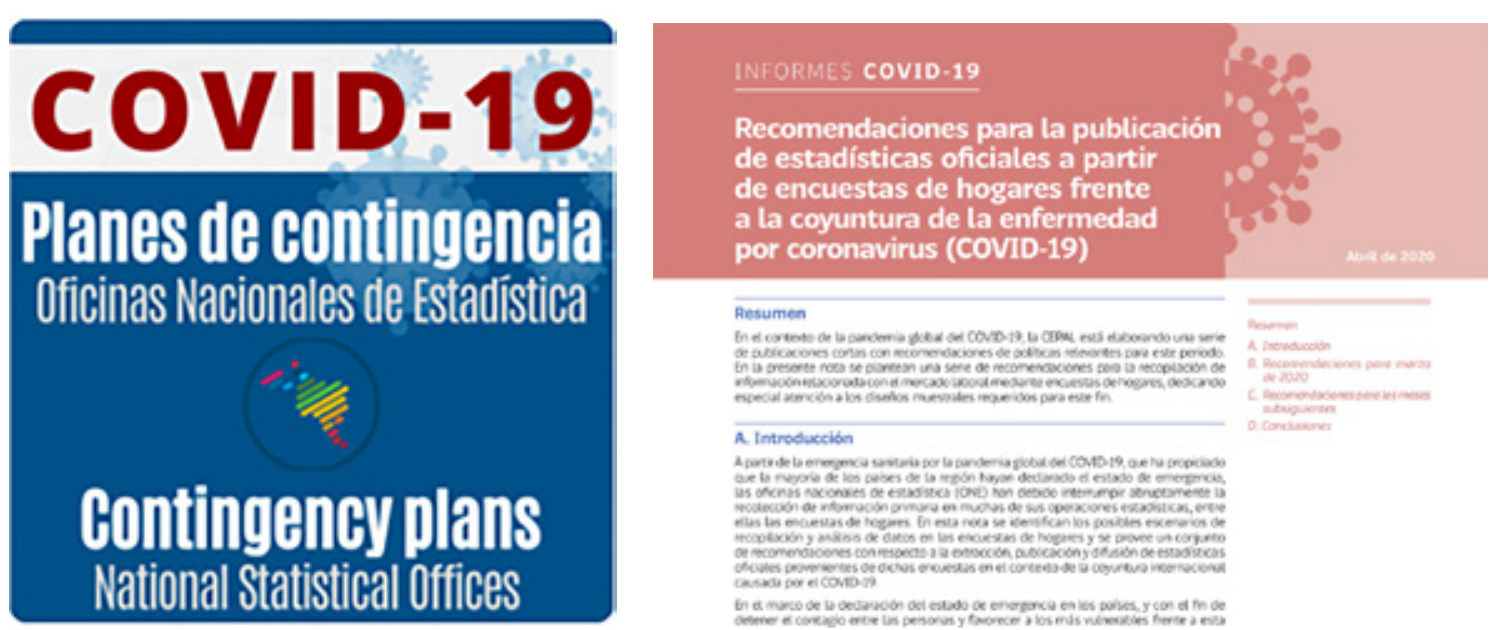

Fuente: Comisión Económica para América Latina y el Caribe (CEPAL), Red de Transmisión del Conocimiento de la Conferencia Estadística de las Américas [en línea] https://rtc-cea.cepal.org/es.

La CEPAL, en colaboración con la Organización Internacional del Trabajo (OIT) y el Instituto Nacional de Estadísticas (INE) de Chile — país coordinador de la Red de Transmisión de Conocimiento-, ha realizado videoconferencias con las oficinas de estadísticas de los países para atender sus inquietudes y brindar asistencia técnica. La Red cuenta con una página web dedicada a difundir las publicaciones y anuncios de las organizaciones internacionales y las oficinas nacionales de estadística sobre las recomendaciones y los planes de contingencia adoptados ${ }^{3}$.

\section{Documentos}

\section{Informe Especial COVID-19, $\mathrm{N}^{\circ} 1$, “América Latina y el Caribe ante la pandemia del COVID-19: efectos económicos y sociales", $\mathrm{N}^{\circ} 2$, “Dimensionar los efectos del COVID-19 para pensar en la reactivación" y $\mathrm{N}^{\circ} 3$, "El desafío social en tiempos del COVID-19"}

Estos informes presentan información y análisis para los encargados de formular políticas y el público en general sobre los impactos socioeconómicos de la pandemia, y proporcionan elementos para la formulación de políticas basadas en evidencia para reaccionar ante la crisis. Los informes especiales se publican periódicamente y abordan los impactos de la pandemia en temas específicos (véase la imagen 5).

En el primer informe se estudiaron los canales de transmisión de la crisis en las economías de la región. Entre los canales externos, se analizó la dinámica del comercio internacional, los precios de los productos básicos y las remesas. El análisis de los efectos internos tomó en cuenta los impactos de las medidas de contención sobre distintos sectores económicos e identificó los más expuestos a la interrupción de actividades. 
- Imagen 5

Informes Especiales COVID-19, números 1, 2 y 3

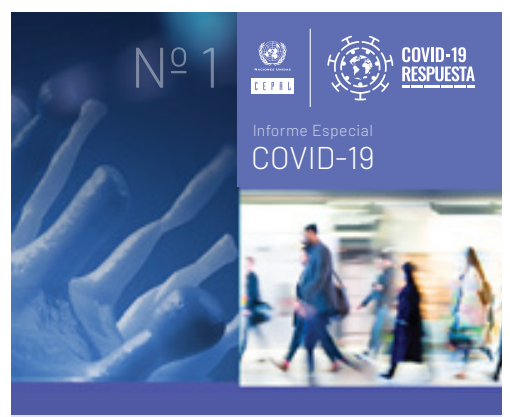

América Latina y el Caribe ante la pandemia del COVID-19

Efectos económicos y sociales

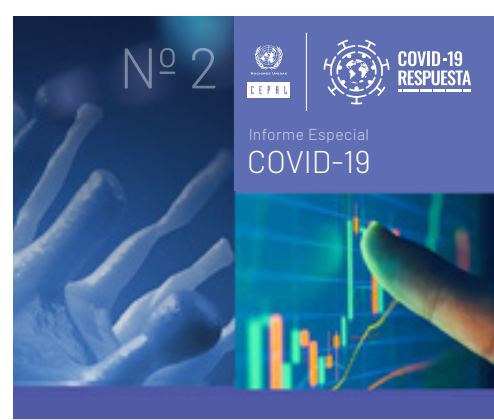

Dimensionar los efectos del COVID-19 para pensar en la reactivación

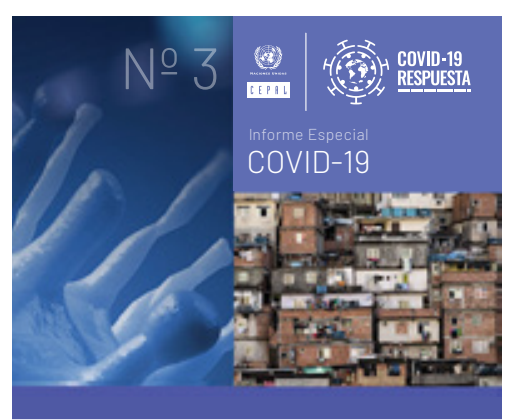

El desafío social en tiempos del COVID-19

Fuente: Comisión Económica para América Latina y el Caribe (CEPAL) [en línea] https://repositorio.cepal.org/bitstream/handle/11362/45337/6/ S2000264_es.pdf y https://repositorio.cepal.org/bitstream/handle/11362/45445/4/S2000286_es.pdf.

Tomando en cuenta los posibles canales de transmisión y la estructura sectorial de las economías, en el segundo informe se presentaron estimaciones de la dinámica de la producción, las exportaciones, el empleo, la pobreza y la distribución del ingreso sobre la base de la información disponible al 17 de abril de 2020. La epidemia del COVID-19 y sus efectos derivados de choques externos e internos en la actividad han llevado a una fuerte revisión a la baja de las proyecciones hechas en diciembre de 2019 en el Balance Preliminar de las Economías de América Latina y el Caribe, 2019 (CEPAL, 2019). Como se mencionó, se espera una caída del PIB de la región del 5,3\% en promedio, la peor contracción desde 1930 y 1914.

Los primeros números del informe analizaron las políticas implementadas por los Gobiernos de la región para enfrentar los efectos sociales y económicos de la pandemia. Más aún, en el tercer Informe Especial se presentó una propuesta de ingreso básico de emergencia equivalente a una línea de pobreza por seis meses para toda la población en situación de pobreza. En los informes también se abordan temas relativos al mundo posterior al COVID-19 y el hecho que la crisis provocará en el mediano plazo cambios estructurales en la organización productiva, el comercio internacional y el actual modelo de globalización.

Hasta la fecha, este es el único informe de alcance latinoamericano y caribeño que presenta escenarios en las dimensiones de evolución del PIB, las exportaciones, el empleo, la pobreza y la distribución del ingreso. En sus próximos números se analizarán los impactos de la pandemia, la seguridad alimentaria, el comercio internacional de productos médicos y el uso de las tecnologías digitales, entre otros.

Repercusión de los primeros dos informes especiales al 30 de abril:

- El Informe Especial No. 2 ha tenido más de 20.000 descargas en el sitio web de la CEPAL.

- El Informe Especial No. 1 ha tenido más de 40.000 descargas. Esta cifra es la más alta desde que la CEPAL mide el número de descargas de sus publicaciones (incluye descargas de las versiones del documento en español e inglés). 


\section{COVID-19: recomendaciones generales para la atención a personas mayores desde una perspectiva de derechos humanos ${ }^{4}$}

Este documento se enfoca en los protocolos de atención para que las medidas que se implementen protejan los derechos humanos de las personas mayores. Sirvió de base para la elaboración del protocolo de atención para personas mayores de la Ciudad de México, se utilizó en las recomendaciones que la Defensoría del Pueblo del Perú realizó al Ministerio de Desarrollo e Inclusión Social, es una referencia para organizaciones sociales de Chile y México, y es utilizado como insumo para las directrices sobre el tema que está elaborando la Oficina del Alto Comisionado de las Naciones Unidas para los Derechos Humanos (ACNUDH). Asimismo, ha sido difundido por organizaciones de personas mayores de Europa y la OMS en Ginebra.

\section{La pandemia del COVID-19 profundiza la crisis de los cuidados en América Latina y el Caribe ${ }^{5}$}

Este documento presenta un diagnóstico de la crisis de cuidados en América Latina y el Caribe y destaca la vigencia del Compromiso de Santiago en el que los Gobiernos de la región acuerdan "Implementar políticas contracíclicas sensibles a las desigualdades de género para mitigar los efectos de crisis y recesiones económicas en la vida de las mujeres, y promover marcos normativos y políticas que dinamicen la economía en sectores clave, incluido el de la economía del cuidado." La pandemia ha puesto de relieve, de forma inédita, la importancia de los cuidados para la sostenibilidad de la vida y la injusta organización social de los mismos en la región. Muestra, además, que hay una insuficiente visibilidad de ese componente fundamental del desarrollo que frecuentemente es considerado solo como una externalidad. Por ello, urge formular las respuestas a las necesidades de cuidados desde un enfoque de género, ya que son las mujeres quienes, de forma remunerada o no remunerada, realizan la mayor parte de esas tareas.

\section{Impacto de las políticas restrictivas al comercio internacional de medicamentos e insumos médicos}

Un estudio sobre la vulnerabilidad de la región ante las restricciones impuestas por más de 70 países a la exportación de medicamentos e insumos médicos indispensables para la lucha contra el COVID-19. Sus mensajes son: i) la región depende casi totalmente de las importaciones extrarregionales de productos médicos, ii) las restricciones a las exportaciones dificultan el abastecimiento de productos esenciales, como equipos de protección personal y ventiladores mecánicos, iii) entre los países que han restringido sus exportaciones de esos productos se incluyen cuatro de los cinco mayores proveedores de la región (Estados Unidos, la Unión Europea, India y Suiza) —China es la excepción-, iv) la mayor fuente de vulnerabilidad son las restricciones introducidas por los Estados Unidos, el principal proveedor de productos médicos, y v) la región debe fortalecer sus capacidades productivas en las industrias farmacéutica y de insumos y aparatos médicos.

\section{Impactos en el turismo}

Un próximo estudio sobre el impacto de la pandemia sobre el turismo describirá su importancia en la economía y el empleo de los países en la región, examinará los efectos de las restricciones a los viajes, analizará escenarios sobre el impacto de la crisis en los ingresos, el empleo y el PIB del sector en 2020, y presentará las medidas implementadas y propuestas para mitigar esos impactos y avanzar en la reactivación del sector. 


\section{Reuniones virtuales}

En más 40 días de operación en la modalidad teletrabajo, se han realizado reuniones con representantes de gobierno al más alto nivel vinculadas a los temas del plan de trabajo, el quehacer de los órganos subsidiarios de la CEPAL y la crisis del COVID-19. En ellas han participado representantes de organismos, fondos y programas de Naciones Unidas, así como los coordinadores residentes, actores clave en la implementación de las acciones sobre el terreno.

24 de marzo a 15 de abrill. Reunión de autoridades de organismos nacionales de estadística. A través de la Red de Transmisión del Conocimiento de la Conferencia Estadística de las Américas (Conectados RTC), se realizaron seis reuniones virtuales de las oficinas e institutos nacionales de estadística, organizadas por la CEPAL, junto con la OIT y el INE de Chile, con el fin de que los países de América Latina y el Caribe evaluaran los impactos de la pandemia en las operaciones estadísticas. La CEPAL informó de los resultados de un cuestionario enviado previamente a las oficinas nacionales de estadística y bancos centrales para conocer los efectos de la emergencia sanitaria en el funcionamiento de las instituciones estadísticas. Se obtuvo la respuesta de 20 países y todos declararon encontrarse en algún tipo de emergencia sanitaria. El compromiso de las oficinas nacionales de estadística y el reconocimiento a la Conferencia Estadística de las Américas de la CEPAL facilitaron el trabajo a distancia.

2 y 21 de abrill. En el ámbito de la Conferencia Regional sobre Desarrollo Social de América Latina y el Caribe, se realizó la reunión virtual El Rol de los Ministerios de Desarrollo Social ante la Pandemia del COVID-19 con la participación de titulares de ministerios y secretarías de desarrollo social. La reunión se desarrolló en dos sesiones: los representantes de los países de América Latina se reunieron el 2 de abril y los de los países del Caribe el 21 de abril. Sumadas ambas sesiones, participaron 29 representantes de Estados miembros y 10 representantes de miembros asociados.

Se analizaron los principales problemas socioeconómicos y las prioridades en materia de protección social; las dificultades, desafíos y aprendizajes en la respuesta a la crisis y las necesidades de cooperación. Todos los países están implementando medidas para mitigar el impacto de la crisis, centradas en reducir los costos humanos en términos de vidas, evitar la profundización de la pobreza y la pobreza extrema, y prevenir los retrocesos en la protección de derechos. Intentan sostener los ingresos de las familias mediante recursos monetarios o en especie (por ejemplo, asistencia alimentaria). Todos resaltaron el impacto de la crisis en la población en situación de pobreza y el recurso a las transferencias condicionadas extraordinarias para paliar la falta de ingresos propios en el contexto de la paralización de actividades que afecta, en particular, a los trabajadores por cuenta propia.

Las acciones se implementan de manera mancomunada ministerios de otras áreas (economía, finanzas, salud, educación) y se han establecido instancias de diálogo y apoyo técnico a los gobiernos (mesas que incorporan a universidades, colegios médicos, sector privado y otros). Las mayores dificultades son: i) las limitaciones de los sistemas de información y registro de población, particularmente la que no forma parte de la población objetivo tradicionalmente atendida por los ministerios de desarrollo social, y los sectores informales, y ii) la manera de que los servicios lleguen a los más vulnerables debido a limitaciones en la inclusión financiera y a problemas operacionales en momentos de aislamiento físico y restricción de movimientos de la población. Se destacó que la urgencia no debe limitar la mirada de futuro de los desafíos de largo plazo ${ }^{6}$.

8 de abrill. Reunión técnica Desafíos y necesidades de los Ministerios de Desarrollo Social ante la pandemia del COVID-19. Su objetivo fue compartir aprendizajes, intercambiar experiencias e identificar áreas de asistencia técnica mutua y de parte de la cooperación internacional en temas y aspectos urgentes definidos por los gobiernos durante la atención a la población en la pandemia. Las

6 Véase CEPAL, "Alicia Bárcena llama a implementar políticas universales, redistributivas y solidarias para evitar otra década perdida" [en línea] https://www.cepal.org/es/noticias/alicia-barcena-llama-implementar-politicas-universales-redistributivas-solidarias-evitar y "Alicia Bárcena alentó a los países del Caribe a avanzar hacia sociedades menos desiguales y más solidarias, sin dejar a nadie atrás" [en línea] https://www. cepal.org/es/noticias/alicia-barcena-alento-paises-caribe-avanzar-sociedades-menos-desiguales-mas-solidarias-sin. 
dificultades y desafíos destacados se centraron en la gestión y la calidad de las fuentes de datos, particularmente para seleccionar y acceder a la población destinataria de las acciones. Se destacó la utilidad de incorporar acciones basadas en las tecnologías digitales y modelos innovadores de gestión, así como la importancia de mantener la mirada de mediano y largo plazo, al tiempo que se atiende la emergencia. Se destacó el trabajo interinstitucional y con las organismos, fondos y programas de las Naciones Unidas.

8 de abrill. Reunión informativa entre las ministras y altas autoridades de los mecanismos para el adelanto de la mujer de América Latina y el Caribe: La Respuesta a la Crisis de la Pandemia COVID-19 desde la Perspectiva de Género. Fue organizada por la CEPAL y la Entidad de las Naciones Unidas para la Igualdad de Género y el Empoderamiento de las Mujeres (ONU-Mujeres) y en ella participaron representantes de 29 países de la región. Se presentaron el documento La pandemia del COVID-19 profundiza la crisis de los cuidados en América Latina y el Caribe y un mapeo de iniciativas impulsadas por los Gobiernos de América Latina y el Caribe para abordar las dimensiones de género en la respuesta a la pandemia del COVID-198.

Los temas centrales de la reunión fueron la manera en que, en el contexto del aislamiento social, se acentúa la desigual distribución de las tareas de cuidado y cómo el permanecer en casa ha incrementado las situaciones de violencia física, psíquica y económica contra las mujeres. Se hizo énfasis en la importancia de la Estrategia de Montevideo para la Implementación de la Agenda Regional de Género en el Marco del Desarrollo Sostenible hacia 2030 y el Compromiso de Santiago como instrumentos regionales para que las respuestas a la pandemia tengan un enfoque integral. Se intercambió información en torno a las principales iniciativas en áreas como la prevención de la violencia contra las mujeres, la promoción de la corresponsabilidad de los cuidados y la protección de los empleos e ingresos de las mujeres. Como resultado, la CEPAL está incorporando las iniciativas de los gobiernos sobre igualdad de género en el Observatorio COVID-19 y seguirá promoviendo espacios de intercambio y de cooperación regional que permitan impulsar una respuesta coordinada a la crisis desde una perspectiva de género ${ }^{9}$.

13 de abril. Reunión virtual de ministras y ministros de finanzas de América Latina y el Caribe para compartir experiencias sobre las respuestas fiscales a la crisis generada por la pandemia del COVID-19. En las presentaciones se hizo referencia a objetivos comunes en las estrategias para controlar la pandemia y mitigar sus efectos sociales y económicos. Entre las medidas implementadas destacan los aumentos de los presupuestos de los sistemas de salud pública para expandir su capacidad de atención, el fortalecimiento de las redes de protección social con transferencias para compensar las pérdidas de ingresos de los trabajadores formales e informales, las líneas de crédito para proveer de liquidez a las empresas, especialmente a las pequeñas y medianas empresas (pymes), que permitan proteger la capacidad productiva de la economía y las medidas de alivio tributario para proveer de liquidez de corto plazo a los contribuyentes. Los países coincidieron en la importancia de celebrar reuniones virtuales adicionales para continuar compartiendo información y fomentar el diálogo regional sobre iniciativas para abordar problemáticas fiscales compartidas.

Se está organizando el capítulo de esta reunión correspondiente a los países del Caribe - tanto países miembros como asociados- cuyas economías son particularmente afectadas por la caída del comercio con los Estados Unidos, su dependencia los productos importados y la pérdida total de ingresos por la suspensión del turismo.

21 de abrill. Virtual Latin America Meeting: Impacto en la industria marítima de la región durante la crisis global de COVID-19, organizada conjuntamente con la Asociación Internacional de Mujeres en el Sector del Comercio y el Transporte Marítimo (WISTA) y la Red de Mujeres de Autoridades Marítimas de Latinoamérica (Red MAMLa). Participaron representantes de la Argentina, Chile, Colombia, México, Panamá, el Perú, la República Bolivariana de Venezuela y el Uruguay.

23 de abrill. Retos del sector portuario colombiano fue la reunión organizada con la Asociación Nacional de Empresarios de Colombia (ANDI) y la Agencia Nacional de Infraestructura (ANI) de Colombia.

Véase CEPAL (2020c).

Véase [en línea] https://data2.unhcr.org/en/documents/download/75750.

Véase CEPAL, "Ante la mayor exposición de las mujeres, la CEPAL llama a los Estados a garantizar sus derechos en el marco de la pandemia del

COVID-19" [en línea] https://www.cepal.org/es/comunicados/la-mayor-exposicion-mujeres-la-cepal-llama-estados-garantizar-sus-derechos-marco-la. 


\section{E. Reuniones programadas}

Reunión virtual con ministros y autoridades de planificación de América Latina y el Caribe. Se está organizando con la Oficina de Planeamiento y Presupuesto (OPP) del Uruguay, país que preside el Consejo Regional De Planificación (CRP), para analizar los impactos de la crisis del COVID en materia de planificación, territorio y presupuestos. Se estima que la reunión se realice en el mes de mayo.

Reunión de autoridades en materia de envejecimiento y personas mayores en América Latina y el Caribe. Organizada en coordinación con el Paraguay, país que preside la Cuarta Conferencia Regional Intergubernamental sobre Envejecimiento y Derechos de las Personas Mayores en América Latina y el Caribe, su objetivo es analizar los impactos del COVID-19 en las personas mayores.

Reunión de organizaciones de la sociedad civil de América Latina y el Caribe. Se está organizando con el Centro de Pensamiento Estratégico Internacional (CEPEI) con participantes de la sociedad civil de la región para examinar las actividades que llevan a cabo en el marco de la pandemia. Se espera una amplia convocatoria de actores basada en la red de organizaciones de la sociedad civil que participan en el Foro de los Países de América Latina y el Caribe sobre el Desarrollo Sostenible y en el Mecanismo de participación de sociedad civil en la Agenda de Desarrollo Sostenible. 
- Cuadro 5

Medidas anunciadas por los países para enfrentar la pandemia

Los paises de la región han implementado medidas inmediatas para contener el virus, proteger la fuerza laboral y los ingresos de los hogares

- Medidas de restricción y monitoreo de viajeros de zonas afectadas por el COVID-19.

- Prohibiciones de vuelo (desde y hacia países específicos) y cierre de fronteras.

- Aprendizaje a distancia y educación en el hogar (con asimetrías en la conectividad).

- Distanciamiento social con cierre de restaurantes, bares, cines, promoción del teletrabajo y reducción del horario de oficina.

- Fortalecimiento de la capacidad del sector de la salud en cuanto a camas, hospitales móviles y suministros médicos; la infraestructura de salud en la región está fragmentada y es insuficiente (poco más de dos camas por cada 1.000 personas).
- Cuarentenas totales o parciales con acuerdos laborales que incluyen medidas legales para teletrabajo, reducción de horas de trabajo, introducción de horarios flexibles, vacaciones adelantadas y protección a los trabajadores de los despidos.

- Protección de la fuerza laboral y de los ingresos mediante apoyo salarial para compensar pérdidas de ingresos con pagos adelantados, subsidios salariales o a través del fortalecimiento del seguro de desempleo, suspensión o reducción de los pagos de contribuciones de servicios de agua, gas y electricidad o a fondos de pensiones privados.

- Protección social para reducir el impacto social en los más pobres mediante subsidios, transferencias de efectivo o pagos adelantados, programas sociales y mecanismos de protección social.

- Apoyo financiero especial para pymes, otras empresas y el sector informal mediante la renegociación y la mejora de las condiciones de crédito bancario.

- Medidas monetarias y financieras para preservar la liquidez de los bancos, apoyar el comercio y abordar deudas públicas y privadas; reducción de tasas de interés de los bancos centrales y apertura de líneas de crédito especiales, emisión de préstamos adicionales, ampliación de los plazos para el reembolso de los créditos (consumidores y empresas) o extensión de hipotecas.

- Medidas fiscales que incluyen la flexibilidad para redirigir presupuestos estatales, proceder a la desgravación fiscal, retrasar los plazos de presentación de declaraciones de impuestos o exenciones de impuestos para ciertos sectores económicos; los ministros de finanzas deberán reorganizar los presupuestos y buscar financiamiento adicional para canalizar recursos hacia medidas urgentes a corto plazo. La Argentina, Bahamas, Barbados, Belice, el Brasil, Chile, Colombia, Guatemala, Honduras, Jamaica, el Paraguay, el Perú, Trinidad y Tabago y el Uruguay han implementado paquetes fiscales que van del $0,6 \%$ a más del $10 \%$ del PIB si se incluyen las garantías estatales a créditos.

- Medidas para preservar la capacidad productiva y crear condiciones para la reactivación de la actividad económica a través de mecanismos de liquidez para empresas, en particular para las pymes.

- Medidas de expansión de los sistemas de protección social para llegar a trabajadores subempleados o autónomos, jóvenes, mujeres, niños, niñas y personas mayores.

Fuente: Comisión Económica para América Latina y el Caribe (CEPAL).

Las medidas de estímulo fiscal ante la crisis humanitaria y económica resultarán en un aumento considerable de los déficits fiscales y los niveles de deuda. Por ello, es necesario renovar los pactos fiscales en muchos países de la región para enfrentar futuros ajustes y minimizar los riesgos financieros.

En materia de política social, entre el 13 de marzo y el 24 de abril de 2020, 29 países adoptaron 126 medidas de protección social en apoyo a los hogares más pobres, vulnerables y precarizados. El número de países y de medidas aumentó casi diariamente durante la segunda mitad del mes de marzo (véase el gráfico 4).

Las medidas más frecuentes han sido la entrega de alimentos y nuevas transferencias monetarias (33\% y $27 \%$ del total, respectivamente), seguidas por la suspensión del pago de servicios básicos (agua, energía, teléfono e Internet) y el aumento del monto de transferencias monetarias existentes ( $19 \%$ y $13 \%$, respectivamente). Las medidas de anticipo de entrega de programas de transferencias existentes representaron el $5 \%$ del total, y el aumento de la cobertura poblacional de las transferencias monetarias existentes, el $4 \%$ (véase el gráfico 5). Es importante señalar que varios de los programas de transferencias monetarias existentes han suspendido sus condicionalidades debido, por ejemplo, a que las familias no pueden enviar a sus hijos e hijas a la escuela. 
- Gráfico 4

América Latina y el Caribe ( 29 países $\left.^{a}\right)$ : medidas de protección social para la población en situación de pobreza y vulnerabilidad anunciadas para enfrentar la pandemia, 13 de marzo a 24 de abril de 2020 (En número de medidas, información diaria)

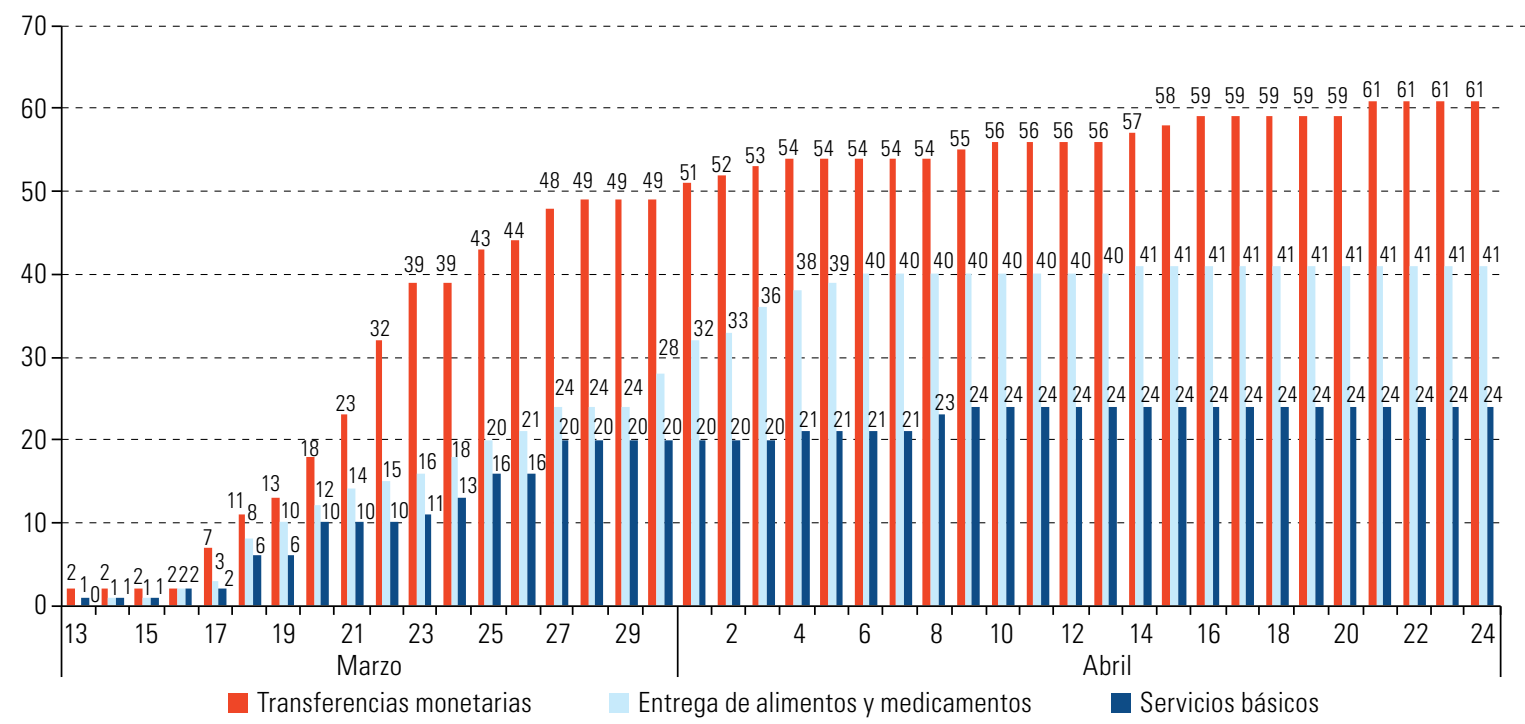

Fuente: Comisión Económica para América Latina y el Caribe (CEPAL).

a Los países considerados son: Antigua y Barbuda, Argentina, Bahamas, Barbados, Belice, Bolivia (Estado Plurinacional de), Brasil, Chile, Colombia, Costa Rica, Cuba, Ecuador, El Salvador, Granada, Guatemala, Guyana, Haití, Honduras, Jamaica, México, Panamá, Paraguay, Perú, República Dominicana, San Vicente y las Granadinas, Santa Lucía, Trinidad y Tabago, Uruguay y Venezuela (República Bolivariana de).

\section{- Gráfico 5}

América Latina y el Caribe ( 29 países ${ }^{a}$ : medidas de protección social para la población en situación de pobreza y vulnerabilidad anunciadas para enfrentar los efectos de la pandemia del COVID-19, por tipo de medida, al $\mathbf{2 4}$ de abril de 2020

(En número de medidas y distribución porcentual)

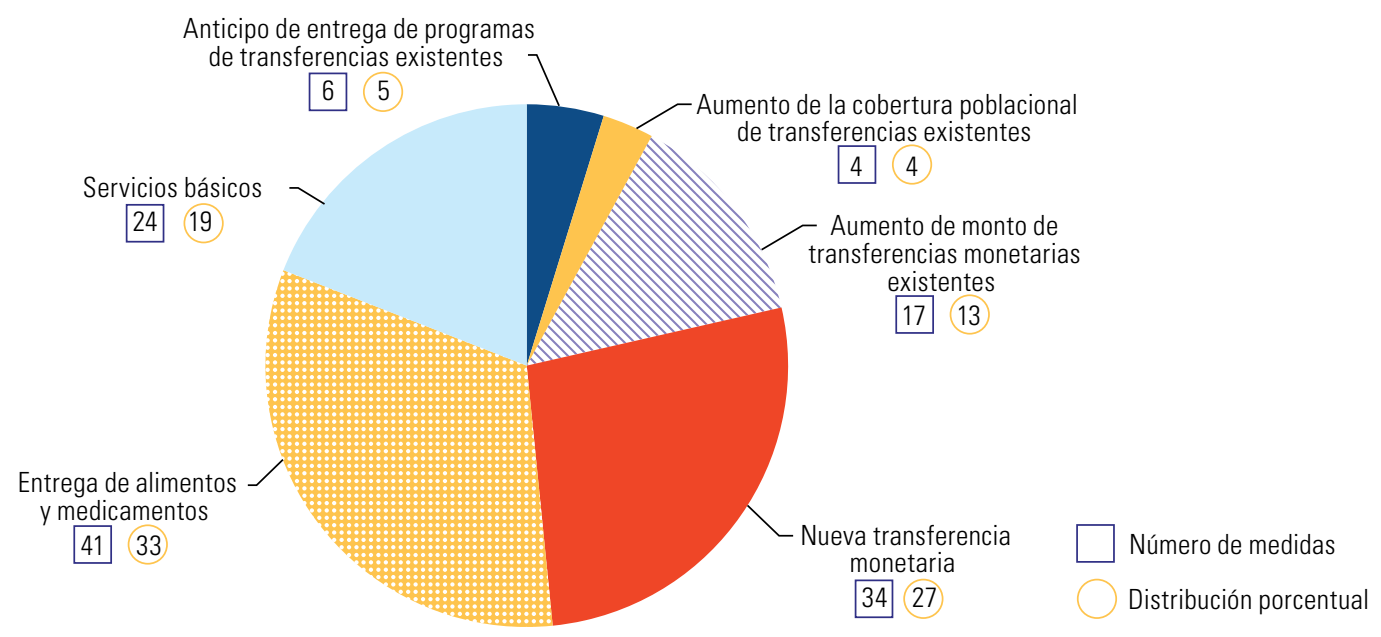

Fuente: Comisión Económica para América Latina y el Caribe (CEPAL).

a Los países considerados son: Antigua y Barbuda, Argentina, Bahamas, Barbados, Belice, Bolivia (Estado Plurinacional de), Brasil, Chile, Colombia, Costa Rica, Cuba, Ecuador, El Salvador, Granada, Guatemala, Guyana, Haití, Honduras, Jamaica, México, Panamá, Paraguay, Perú, República Dominicana, San Vicente y las Granadinas, Santa Lucía, Trinidad y Tabago, Uruguay y Venezuela (República Bolivariana de). 


\section{B. Políticas para seguir avanzando en la mitigación de los efectos de la crisis}

Los paquetes fiscales anunciados en la región fueron la primera respuesta al impacto socioeconómico de la pandemia. Se requerirán esfuerzos adicionales en la medida que aumente la magnitud de la crisis. Por lo tanto, es necesario expandir el espacio fiscal, lo que exige acceder a condiciones de financiamiento favorables.

Un número cada vez mayor de países de la región han solicitado financiamiento de emergencia a las instituciones financieras internacionales, como el Fondo Monetario Internacional (FMI), el Banco Mundial , el Banco Interamericano de Desarrollo (BID) y el Banco de Desarrollo de América Latina (CAF), que han ampliado el acceso al crédito a los países miembros. Es importante que estas instituciones continúen facilitando líneas de crédito a bajo costo y de forma ágil, además de revisar las condicionalidades en el financiamiento de emergencia y flexibilizar las políticas de préstamos concesionales y de graduación de los países de renta media.

La condonación y el alivio del servicio de la deuda, que incluya a los países de ingresos medios de la región que lo requieran, aumentaría significativamente su espacio fiscal. Las economías altamente endeudadas deben beneficiarse de alivios oficiales de la deuda o de suspensiones generosas de sus obligaciones, así como de reestructuraciones de deuda. Abordar la problemática de la deuda es urgente, y debe comenzarse por los acreedores oficiales para luego atraer a los acreedores privados. Las quitas de deuda deberían combinarse con mecanismos innovadores de financiamiento cuando la deuda sea una característica estructural de las economías. Ya que para muchos países parte de los acreedores pertenecen al sector privado, es necesario establecer un mecanismo internacional de reestructuración de la deuda soberana.

Otras medidas para ampliar el espacio fiscal y mejorar las condiciones de acceso al financiamiento son la revisión de las leyes de responsabilidad y reglas fiscales procíclicas — que solo se enfocan en el gasto y no en los ingresos-y lograr que las agencias calificadoras consideren en sus metodologías de evaluación de riesgo que el deterioro de las posiciones fiscales de los países para enfrentar la crisis es extraordinario y temporal.

Por su parte, los bancos centrales de la región han anunciado "medidas poco convencionales" para expandir la liquidez, que incluyen la compra de activos públicos y privados. Esto hace necesario una mayor coordinación entre las autoridades fiscales y monetarias para financiar los paquetes de estímulos anunciados, ya sea mediante la compra de títulos emitidos por el sector público directamente o mediante el uso de activos externos para financiar el incremento del gasto.

Se requiere coordinación entre los actores para determinar la manera y el tiempo necesarios para "normalizar" la política monetaria en la región. También es preciso aumentar la coordinación entre la política fiscal y la política monetaria, así como entre los bancos centrales y los entes de supervisión y regulación bancaria para garantizar que estos recursos sean canalizados a los hogares y a los sectores productivos que lo necesiten, y que no pasen a formar parte de las reservas de las instituciones financieras o alimentar la demanda de activos externos.

Dada la magnitud de los choques, es necesario adecuar las herramientas macroprudenciales empleadas para atenuar la volatilidad cambiaria y las depreciaciones excesivas de las monedas. El acceso a divisas, particularmente a dólares, se ha vuelto cada vez más limitado para los países en desarrollo y los mercados emergentes. Aunque el establecimiento de líneas de intercambio (swaps) entre la Reserva Federal de los Estados Unidos y los bancos centrales del Brasil y México es un primer paso, el resto de la región se encuentra fuera de ese mecanismo de apoyo.

Una forma adicional de ampliar el acceso de todos los países a la liquidez en dólares estadounidenses sería mediante una emisión a gran escala de derechos especiales de giro (DEG), posiblemente mayor a la efectuada en 2009, cuando el FMI emitió DEG por 250.000 millones de dólares para ayudar a combatir la crisis financiera mundial, conforme a la propuesta del Grupo de los 20 (G20). 
En este contexto, para enfrentar los impactos socioeconómicos de la crisis, la CEPAL propuso que los Gobiernos de la región garanticen transferencias monetarias temporales para satisfacer necesidades básicas y sostener el consumo de los hogares, lo que será crucial para la reactivación. Desde una perspectiva de largo plazo, la CEPAL reiteró que el alcance de esas transferencias debe ser permanente, ir más allá de las personas en la pobreza y llegar a amplios estratos de la población vulnerables a caer en ella. Esto permitiría avanzar hacia un ingreso básico universal que se implementaría gradualmente en un período definido de acuerdo con la situación de cada país.

En la coyuntura de la crisis del COVID-19, es necesario manejar alternativas más acotadas y de menor alcance temporal, pero que señalen el camino para las acciones que se implementarían una vez superada la pandemia. Teniendo en cuenta el limitado espacio fiscal de los países de la región, la alternativa más viable es hacer transferencias de un monto igual a una línea de pobreza durante seis meses, que permitirían cubrir una canasta básica de alimentos, así como otras necesidades básicas. Su implementación demandaría un gasto adicional del 2,8\% del PIB para abarcar a todas las personas que se encontrarán en situación de pobreza en 2020. Esta propuesta debe ser ajustada o expandida según las situaciones nacionales.

\section{Políticas para el cambio estructural: creación del mundo post COVID}

La pandemia ha alterado las relaciones económicas y sociales de un modo radical y sus consecuencias trascenderán su duración. Es altamente probable que sea un catalizador de los cambios que se observaban en la configuración de la producción y el comercio a nivel mundial en la última década. El modelo de globalización basado en redes internacionales de producción con una elevada dispersión geográfica mostraba signos de agotamiento visibles en el estancamiento secular de muchas economías, la pérdida de dinamismo del comercio y la alta volatilidad desde la crisis financiera mundial. Más recientemente, las restricciones sin precedentes al transporte internacional adoptadas por numerosos países han ocasionado masivas perturbaciones en las cadenas globales de valor.

Desde la irrupción del COVID-19, las nuevas órdenes manufactureras mundiales han sufrido la caída más rápida de los últimos 11 años. Si bien China ha retomado gradualmente las actividades productivas, enfrenta limitaciones por el lado de la oferta, debido a la reducción de las importaciones desde Europa y los Estados Unidos y a una demanda mundial muy debilitada, lo que no hace prever una pronta recuperación de la manufactura mundial. Las existencias mundiales de insumos cayeron bruscamente como resultado de las limitaciones de la oferta y muchos países están informando de falta de insumos, especialmente en los sectores que producen bienes para hacer frente a la emergencia sanitaria.

La expansión de la crisis productiva ha puesto de manifiesto las vulnerabilidades de la interdependencia, a nivel de países y empresas, y puede llevar a cambios significativos en la organización de la producción a nivel global.

En primer lugar, ha quedado en evidencia la vulnerabilidad de las redes internacionales de producción ante fenómenos imprevistos de gran magnitud y la consecuente necesidad de dotarlas de una mayor resiliencia. Desde la óptica de las empresas multinacionales que lideran esas redes, esto implica diversificar su red de proveedores en términos de países y empresas, privilegiar ubicaciones más cercanas a los mercados finales de consumo (nearshoring) y relocalizar procesos críticos cuando sea económicamente factible mediante el uso de tecnologías como la manufactura aditiva. Hay muestras de movimientos en este sentido en las principales economías mundiales:

- El Japón ha destinado 2.200 millones de dólares de su paquete de estímulo económico frente al COVID-19 para ayudar a sus empresas a relocalizar la producción fuera de China.

- En los Estados Unidos, el índice de relocalización alcanzó su valor máximo en 2019 debido a las tensiones comerciales con China, mientras que el peso de México en las importaciones manufactureras aumentó marcadamente respecto de los proveedores asiáticos (Kearney, 2020). Las perturbaciones ocasionadas por el COVID-19 reforzarían ambas tendencias. 
- En la Unión Europea, más de 200 empresas relocalizaron su producción entre 2016 y 2019. El $50 \%$ de los casos de relocalización proviene de actividades deslocalizadas dentro de la propia Unión Europea, mientras que China representa el 32\% y la India el 5\% de la misma (Fundación Europea para la Mejora de las Condiciones de Vida y de Trabajo, 2019).

En segundo lugar, la crisis ha obligado a las empresas a adecuar su funcionamiento interno a las medidas de distanciamiento social. A medida que la robótica, la automatización y el uso masivo de plataformas de teletrabajo se vuelven más eficientes, más económicas y fáciles de implementar, es probable que la automatización de algunos sectores y procesos productivos se acelere, con impactos sobre el empleo.

En tercer lugar, en el plano de la gobernanza del comercio mundial, el COVID-19 ha profundizado el debilitamiento de la cooperación internacional y del multilateralismo que se observa hace ya algunos años. Así lo evidencian las restricciones a la exportación de productos médicos y sanitarios y de alimentos adoptadas por países de todas las regiones. En este contexto, y en forma consistente con un escenario de acortamiento de las redes internacionales de suministro, resulta probable que los esfuerzos de los principales actores del comercio mundial se vuelquen hacia los acuerdos regionales en detrimento de los multilaterales. Tal escenario llevaría a un comercio mundial más fragmentado y con mayor ocurrencia de conflictos, en un momento en que la capacidad de la Organización Mundial del Comercio (OMC) de resolver las controversias entre sus miembros se encuentra reducida al mínimo.

En conclusión, cabe esperar que la pandemia refuerce tendencias que ya se observaban y que apuntan a un menor nivel de interdependencia productiva y comercial entre las principales economías mundiales, en particular entre los Estados Unidos y Europa, por una parte, y China, por la otra. Ese proceso se vería favorecido por los avances en materia de digitalización y robotización, que reducen la importancia relativa de los bajos costos laborales como factor de competitividad. El resultado neto no sería una reversión de la globalización, sino una economía mundial más regionalizada, organizada en torno a tres polos productivos ya existentes: América del Norte, Europa y Asia oriental y sudoriental.

Para América Latina y el Caribe, la magnitud del impacto y la capacidad de reacción dependerán en gran medida de la estructura productiva de cada economía, de la participación de sus empresas en las cadenas de valor y de las capacidades productivas existentes.

Como nunca en los últimos 30 años, hoy está abierto a discusión el modelo dominante de inserción de la región en la economía internacional, basado en la especialización en materias primas, manufacturas de ensamblaje y turismo de sol y playa. En efecto, la disrupción de diversas cadenas globales de valor ha mostrado los riesgos que supone la elevada dependencia regional de las manufacturas importadas. Esto ha quedado particularmente de manifiesto en las graves limitaciones a la disponibilidad de productos esenciales para la lucha contra el COVID-19 a raíz de las restricciones impuestas por la mayoría de sus principales proveedores. En este contexto, adquiere una importancia renovada la adopción de políticas industriales y tecnológicas que permitan a la región fortalecer sus capacidades productivas y generar nuevas capacidades en sectores estratégicos. Estos esfuerzos podrían verse facilitados en algunos países por la llegada de nuevas inversiones en el marco del acortamiento de las cadenas de suministro de empresas multinacionales, especialmente estadounidenses.

El contexto internacional post COVID-19 que es posible ir perfilando apunta a una creciente importancia de los procesos de regionalización de la producción. En ese sentido, la integración regional está llamada a desempeñar un papel clave en las estrategias de desarrollo de los países de América Latina y el Caribe. Un mercado integrado, con 650 millones de habitantes, constituiría un importante seguro frente a perturbaciones de oferta o de demanda generadas fuera de la región. Asimismo, permitiría alcanzar la escala requerida para viabilizar nuevas industrias, así como promover redes de producción e investigación compartida entre los distintos países y subregiones. 
La protección social será una política clave para la reducción de las desigualdades, el avance hacia la inclusión social y el crecimiento inclusivo, y, por ende, para la cohesión social. Por ello, los países deberán consolidar sistemas de protección social universales, que incluyan la salud universal, basados en un enfoque de derechos y sensibles a las diferencias, y desarrollar estrategias de inclusión laboral en el período de reactivación. Estos sistemas permiten identificar y responder a los impactos de la crisis en el empleo y las condiciones de vida de las personas, y atender la situación diferenciada que enfrentan diversas poblaciones, con atención oportuna a los trabajadores informales, a los grupos etarios más vulnerables, a los habitantes de áreas rurales y remotas, a los pueblos indígenas y las poblaciones afrodescendientes, a las personas con discapacidad y los migrantes.

Para evitar otra década perdida, los países de la región deben construir Estados de bienestar y sistemas de protección social universal. La crisis financiera internacional de 2008 mostró la importancia del gasto público social contracíclico y de las políticas sociales orientadas a moderar los efectos de la crisis en la economía real y frenar el aumento del desempleo y la pobreza. Por su parte, la crisis de la deuda externa de los ochenta llevó a grandes aumentos de los niveles de pobreza y la región tardó 25 años en retornar a los niveles de pobreza (ya de por sí altos) previos a la crisis. Recordar estas experiencias es importante pues el aumento de la pobreza proyectado por la CEPAL para 2020 implica un retroceso de 13 años (véase el gráfico 6).

- Gráfico 6

América Latina (18 países ${ }^{\mathrm{a}):}$ PIB per cápita e incidencia de la pobreza, 1980-2020

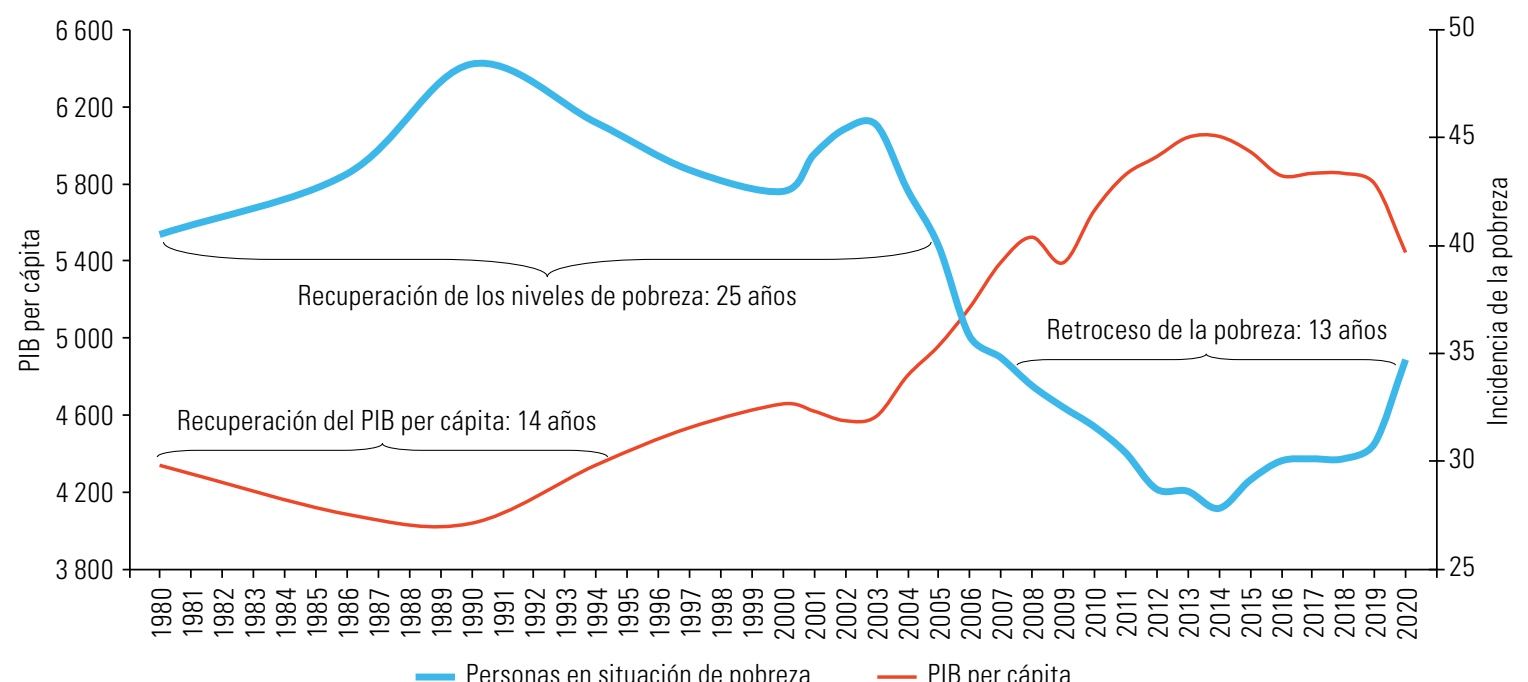

Fuente: Comisión Económica para América Latina y el Caribe (CEPAL), sobre la base de Banco de Datos de Encuestas de Hogares (BADEHOG).

a Los países considerados son: Argentina, Bolivia (Estado Plurinacional de), Brasil, Chile, Colombia, Costa Rica, Ecuador, El Salvador, Guatemala, Honduras, México, Nicaragua, Panamá, Paraguay, Perú, República Dominicana, Uruguay y Venezuela (República Bolivariana de).

b Las cifras de 2019 son datos preliminares; las cifras de 2020 son proyecciones.

\section{Conclusiones duras, pero claras}

- La crisis que sufre la región en 2020, con una caída del PIB del 5,3\%, será la peor en toda su historia. Para encontrar una contracción de magnitud comparable hace falta retroceder hasta la Gran Depresión de la década de 1930 (-5\%) o, más aún, hasta 1914 (-4,9\%).

- Los efectos de mediano plazo en materia de reorganización de la producción y del comercio internacional en términos de localización y tecnológicos son importantes. Los escenarios posibles que aún están abiertos son por lo menos tres: continuación de la globalización, pero sobre la base de nuevos modelos de gobernanza más receptivos al multilateralismo y la corrección de las desigualdades entre países, soluciones de alcance exclusivamente nacional, o una acentuación de la regionalización. 
- Para la gran mayoría de los países de América Latina y el Caribe, las soluciones de alcance exclusivamente nacional no serían viables por razones de economías de escala, tecnológicas y de aprendizaje.

- Es posible que la mejor solución sea una nueva globalización con una gobernanza proclive a la inclusión y la sostenibilidad, pero para participar activamente en esa nueva globalización, América Latina y el Caribe debe integrarse productiva, comercial y socialmente. Para ello, la coordinación de los países de la región en materia macroeconómica y productiva es crucial para negociar las condiciones de la nueva normalidad, particularmente con la urgencia de la actual crisis y en el mediano plazo: las del financiamiento para un nuevo estilo de desarrollo con igualdad y sostenibilidad ambiental.

\section{E. Principales recomendaciones de política}

- Suministrar un estímulo fiscal de un monto suficiente para apoyar los servicios de salud y proteger los ingresos y los empleos. Se debe garantizar el suministro ininterrumpido de bienes esenciales, en particular productos farmacéuticos, alimentos y energía, y el acceso universal a las pruebas y a la atención médica de todos quienes las necesiten. Si bien algunos países tienen un reducido el espacio fiscal, el gasto en salud es prioritario en este momento, especialmente en países con sistemas de atención de la salud débiles y fragmentados.

- Reforzar los sistemas de protección social para apoyar a las poblaciones vulnerables. Implementar programas no contributivos, como las transferencias directas de efectivo a los más vulnerables, y medidas como las prestaciones por desempleo, subempleo y autoempleo, los créditos sin intereses a las pequeñas y medianas empresas para el pago de salarios, y los aplazamientos del pago de préstamos, hipotecas y alquileres. Asimismo, se debe considerar la adopción de medidas como no cobrar las cuentas de agua, luz e Internet a personas de bajos ingresos durante la duración de la pandemia.

- En la coyuntura, la CEPAL llama a implementar un ingreso básico de emergencia durante seis meses por un monto equivalente a una línea de pobreza para toda la población en situación de pobreza. La estrategia de mediano y largo plazo deberá conducir a un Estado de bienestar con protección social universal.

- Los bancos centrales deben asegurar la liquidez de las empresas para garantizar su funcionamiento y la estabilidad del sistema financiero. Las políticas monetarias expansivas no serán suficientes. Los bancos centrales deberán intervenir directamente para proporcionar la liquidez que necesitan los sectores financiero y privado no financiero, en particular para garantizar la plena liquidez del mercado de préstamos bancarios a un día y para evitar la interrupción de las cadenas de pago.

- La cooperación internacional y las organizaciones multilaterales deben diseñar nuevos instrumentos técnicos y financieros para apoyar a los países que se enfrentan a la presión fiscal. Deben, asimismo, considerar la posibilidad de conceder préstamos con bajos intereses y ofrecer alivio y aplazamientos del pago de la deuda para aumentar el espacio fiscal. Los países desarrollados y los países en desarrollo disponen de medios muy diferentes para hacer frente a esta crisis sin precedentes, lo que puede acentuar las desigualdades internacionales. Más aún, algunos países muy endeudados, podrían tener problemas para atender el servicio de sus deudas, reestructurarlas o incrementarlas debido al posible colapso de los mercados financieros, lo que restaría impulso al tan necesario gasto público en salud, protección social y estímulo económico. Los países deben adaptar sus respuestas a las condiciones locales y esas respuestas deben ser reforzadas por la cooperación internacional. 


\section{Bibliografía}

CEPAL (Comisión Económica para América Latina y el Caribe) (2020a), "América Latina y el Caribe ante la pandemia del COVID-19: efectos económicos y sociales", Informe Especial COVID-19, № 1, 3 de abril, Santiago. (2020b), "Dimensionar los efectos del COVID-19 para pensar en la reactivación", Informe Especial COVID-19, $N^{\circ} 2,21$ de abril.

(2020c), "El desafío social en tiempos del COVID-19", Informe Especial COVID-19, № 3, 12 de mayo, Santiago.

Fundación Europea para la Mejora de las Condiciones de Vida y de Trabajo (2019), "European Reshoring Monitor" [en línea] https://reshoring.eurofound.europa.eu/.

(2020d), La pandemia del COVID-19 profundiza la crisis de los cuidados en América Latina y el Caribe, Santiago, abril.

(2019), Balance Preliminar de las Economías de América Latina y el Caribe, 2019 (LC/PUB.2019/25-P), Santiago.

Huenchuan, S. (2020), COVID-19: Recomendaciones generales para la atención a personas mayores desde una perspectiva de derechos humanos (LC/MEX/TS.2020/6/Rev.1), Ciudad de México, Comisión Económica para América Latina y el Caribe (CEPAL).

IFF (Instituto de Finanzas Internacionales) (2020a), "Global Debt Monitor: COVID-19 lights a fuse", 6 de abril [en línea] https://www.iif.com/Portals/0/Files/content/Research/Global\%20Debt\%20Monitor_April2020.pdf. (2020b), "LatAm views: deep recession", 13 de abril [en línea] https://www.iif.com/Portals/0/Files/content/ Research/04_13_2020_latam_views.pdf.

Kearney (2020), "Trade war spurs sharp reversal in 2019 Reshoring Index, foreshadowing COVID-19 test of supply chain resilience" [en línea] https://www.kearney.com/operations-performance-transformation/usreshoring-index.

Oficina del Censo de los Estados Unidos (2018), "American Community Survey (ACS)" [en línea] https://www. census.gov/programs-surveys/acs.

OMC (Organización Mundial del Comercio) (2020), "Trade forecast press conference," 8 de abril [en línea] https://www.wto.org/english/news_e/spra_e/spra303_e.htm.

OMT (Organización Mundial delTurismo) (2020), "Impact assessment of the COVID-19 outbreak on international tourism", 24 de marzo [en línea] https://webunwto.s3.eu-west-1.amazonaws.com/s3fspublic/2020-03/2403Coronavirus.pdf. 
